\title{
Financial Reporting: Long-Term Change of Financial Ratios
}

\author{
Erkki K. Laitinen \\ School of Accounting and Finance, University of Vaasa, Vaasa, Finland \\ Email: erkki.k.laitinen@uva.fi
}

How to cite this paper: Laitinen, E.K. (2018) Financial Reporting: Long-Term Change of Financial Ratios. American Journal of Industrial and Business Management, 8, 1893-1927.

https://doi.org/10.4236/ajibm.2018.89128

Received: April 3, 2018

Accepted: September 1, 2018

Published: September 4, 2018

Copyright (c) 2018 by author and Scientific Research Publishing Inc. This work is licensed under the Creative Commons Attribution International License (CC BY 4.0).

http://creativecommons.org/licenses/by/4.0/

\begin{abstract}
Financial ratios are constructed mathematically as a ratio of numerator and denominator taken from financial statements (income statement or balance sheet). They are useful indicators of financial performance of a firm. However, changes in a particular ratio are difficult to interpret, because they can be related to changes in the numerator, the denominator, or both. Therefore, each change needs an interpretation of its own. The objective of the study is to analyze what kinds of roles have changes in the numerator and the denominator played in the long-term change of a set of financial ratios. The set of ratios consists of seven ratios reflecting profitability and its determinants, liquidity, and long-term solvency. The changes of these ratios are analyzed using the trends of the ratio components for a ten-year period in a sample of 9160 active and 81 bankrupt Finnish firms.
\end{abstract}

\section{Keywords}

Financial Ratios, Ratio Change, Trend Analysis, Financial Statement Analysis, Ratio Interpretation, Finnish Firms, Bankrupt Firms

\section{Introduction}

Financial ratios are widely used by credit analysts, lenders, stock analysts, managers, owners, investors, and other stakeholders to assess the financial performance of a business firm. This analysis is of special importance to outside stakeholders, because it is based on public financial statements which are the main source of information for outsiders. The origins of the analysis can be traced as far back as the late of nineteenth century (Horrigan [1], pp. 284-285). In the initial stages, financial analysis was based on a casual item-by-item basis but when the volume and flow of financial information increased greatly, the relationships between different items, financial ratios, began to come under scru- 
tiny. Financial ratios made it easier compare the financial performance of a business firm with its own history, with competitors (relative ratio criteria), and with empirically justified norms (absolute ratio criteria). However, financial ratio analysis has also several limitations when aggregating information. Mathematically, financial ratios are constructed as ratio variables where the numerator and denominator (components of the ratio) are items taken from financial statements. Gilman [2] as early as in the 1920s criticized ratio measures because their changes over time cannot be interpreted since the numerator and denominator both vary. Consequently, Gilman clearly did not believe that ratios portray fundamental relationships within the business. In this study, the focus of analysis is set on this puzzle of ratio variables.

Financial ratios are in practice used for many kinds of purposes. However, there are two principal uses of financial ratios (Whittington [3]; Barnes [4]). Firstly, the positive use of ratio analysis means to estimate empirical relationships, usually for prediction purposes. There are two types of positive use: Forecasting of future financial variables (profit, loss) using financial ratios (accountants and analysts) and predicting different events (bankruptcy, failure, payment delay) using financial ratios as variables in statistical models (researchers). Secondly, the traditional normative use of ratio analysis is to compare a ratio of a firm with a standard, criterion, or industry-wide average. There is evidence that firms do adjust their financial ratios to such targets (Barnes [4]). This normative analysis can be carried out in two different ways. First, the analyst can examine a ratio across time (for example, 5 - 10 years) to identify a trend (trend analysis, time-series analysis), or, secondly, the analyst can compare the value of a ratio with those of other firms across the same industry (inter-firm analysis, cross-sectional analysis). The practical trend or time-series analysis is exposed to the critique presented by Gilman [2]: It is difficult to interpret the trend of a ratio when both the numerator and denominator change across time. This study concentrates on this kind of trend analysis trying to identify reasons for a financial ratio change.

This study significantly differs from previous time-series studies in financial ratio analysis (Tippett $\&$ Whittington [5]; Whittington \& Tippett [6]; Ioannides, Peel \& Peel [7]; Peel, Peel \& Venetis [8]; McLeay \& Stevenson [9]). These studies mainly concentrate on the conditions and implications of nonstationarity and cointegration in a financial ratio of pure form $R=x / y$. These kinds of studies are important for positive financial ratio analysis, since traditional statistical cross-sectional techniques (regression analysis, discriminant analysis) assume stationarity for the input ratios. Nonstationarity will lead to biased estimates of the model. Cointegration between the ratio components is interesting because it can lead stationarity in the ratio itself (McLeay \& Stevenson [9]). The usual method is to consider the components $x$ and $y$ of a ratio as logarithmic (nonstationary) models often including a deterministic (and sometimes stochastic) trend. In this study, similar logarithmic models with a deterministic trend are applied to components of a set of financial ratios. These models reflect proportionate 
growth in the numerator and denominator of ratio $R=x / y$. However, these models are here not directly used to examine nonstationarity or cointegration. The estimated trends or proportionate growth rates of the components are only used to explain a decrease or an increase (change) in financial ratios in the long term. The objective is to examine whether a long-term change in a financial ratio can be attributed either to positive or to negative trends of the ratio components. In this way, the study is a response to the critique presented by Gillman [2].

Technically, the main reason to use financial ratios is to facilitate comparison across years or firms by adjusting for size. The full control of size assumes that the relation between the ratio components $\mathrm{x}$ and $\mathrm{y}$ is strictly proportional as $x=$ $b y$ (where $y$ is a measure of size) leading to $x / y=b$ (Lev \& Sunder [10]; Barnes [4]). In this case, $b$ as a measure of performance reflects both the marginal and the average effects of a change in $y$ on $x$. If the relation between the components is however for example defined as $x=a+b y$, the change in the ratio $x / y=a / y+$ $b$ reflects the confounding effects of change in the performance $b$, change in the intercept term $a$, and change in $y$, both reflected by $a / y$. The complexity of interpreting these kinds of time-series changes casts doubt on the usefulness of ratios (Lev \& Sunder [10]). Lev \& Sunder ([10], p. 8) conclude that the deviation from proportionality due to an intercept term is probably the most frequently encountered problem with financial data. However, empirical evidence on the violation of the proportionality assumption is mixed (Barnes [4], p. 450). The interpretation of the time-series change in $x / y$ can significantly be facilitated if the change in both $x$ and $y$ is known. If $a>0$ and fixed, an increase in $x$ without an increase in $y$ means that $b$ has increased. Similarly, an increase in $y$ without an increase in $x$ tells that $b$ has decreased. Thus, an analysis of the changes in ratio components can help the analyst to interpret time-series changes in financial ratios even if proportionality is violated.

In summary, the objective of this study is to examine how the long-term change of financial ratios in active and bankrupt firms is associated with the corresponding changes in their components. The contents of the paper is as follows. The second section presents the framework for the analysis where the changes in the ratio components are mathematically examined. In this study, the analysis is not limited to the pure ratios constructed from the non-negative accounting totals as $R=x / y$ (Trigueiros [11]; McLeay \& Stevenson [9]). This analysis will also consider financial ratios defined as $R=(x-z) / y$ where $x, z$, and $y$ are positive accounting totals which makes it possible to analyze a wider set of ratios. In all, seven financial ratios reflecting profitability and its determinants, liquidity, and long-term solvency will be analyzed. The third section presents the empirical data and statistical methods. The changes of ratios are analyzed for a ten-year period in a sample of 9160 active and 81 bankrupt Finnish firms. For bankrupt firms, changes in financial ratios are important indicators of failure risk. The trends (proportionate growth rates) for the components of the ratios are estimated applying the regression analysis on the logarithmic time-series of components. The fourth section presents empirical results. The positive and 
negative changes in the financial ratios are here interpreted using the trends of their components. The results for active and bankrupt firms are compared with each other. Finally, the last section summarizes the main findings of the study.

\section{Framework for the Analysis}

\subsection{Pure Ratios $R=x / y$}

Pure financial ratios are defined as $R=x / y$ where $x(x>0)$ is the numerator and $y(y>0)$ is the denominator. The total change in $R$ can be mathematically presented by the total derivative as follows:

$$
R=\frac{x}{y} \Rightarrow \mathrm{d} R=\frac{1}{y} \mathrm{~d} x-\frac{x}{y^{2}} \mathrm{~d} y
$$

which equals zero if the following equation holds for $d R$

$$
\mathrm{d} R=\mathrm{d} x-\frac{x}{y} \mathrm{~d} y=0 \Rightarrow \frac{\mathrm{d} x}{x}=\frac{\mathrm{d} y}{y} \Rightarrow g(x)=g(y)
$$

where $g(x)$ and $g(y)$ represent the rates of proportionate growth (trends) for $x$ and $y$ respectively. The change in $R$ is either positive or negative when

$$
\begin{array}{ll}
\text { a. } & g(x)>g(y) \Rightarrow \mathrm{d} R>0 \\
\text { b. } & g(x)<g(y) \Rightarrow \mathrm{d} R<0
\end{array}
$$

Thus, in this basic situation the ratio does not change over time when the rates of proportionate growth in numerator $x$ and denominator $y$ are equal. When the growth rate of the numerator exceeds that of the denominator, or when $g(x)>g(y), R$ will increase in time so that $d R>0$. Moreover, when $g(y)>$ $g(x), d R$ will be negative. Therefore, for pure financial ratios based on the relationship between non-negative accounting totals the time-series change can easily interpreted by the trends of the components.

Since $x$ and $y$ are positive accounting totals growing at steady rates, $R$ is also positive and grows at a steady rate itself as follows:

$$
\begin{aligned}
& R(t)=\frac{x(1+g(x))^{t}}{y(1+g(y))^{t}}=\frac{x}{y}(1+g(R))^{t} \\
& g(R)=\frac{g(x)-g(y)}{1+g(y)}
\end{aligned}
$$

where $g(R)=0$ so that $R(t)=R$ if $g(x)=g(y)$ and $g(R)>0$ if $g(x)>g(y)$ conforming to (3).

\subsection{Pure Component Ratios $R=(x-z) / y$}

Secondly, if the numerator of the ratio $x$ is represented by an item that can get negative values, the proportional growth rate $g(x)$ is not appropriate to depict the development (trend) of $x$ in time. In this situation, the ratio $R$ can be defined as $R=(x-z) / y$ where $x, y$, and $z>0$ (positive accounting totals). The total derivative of $R$ in this case is the following: 


$$
R=\frac{x-z}{y} \Rightarrow \mathrm{d} R=\frac{1}{y} \mathrm{~d} x-\frac{1}{y} \mathrm{~d} z-\frac{x-z}{y^{2}} \mathrm{~d} y
$$

which is zero if

$$
\mathrm{d} R=0 \Rightarrow \mathrm{d} x-\mathrm{d} z-\frac{x-z}{y} \mathrm{~d} y=0 \Rightarrow \frac{\mathrm{d} y}{y}=\frac{\mathrm{d} x-\mathrm{d} z}{x-z} \Rightarrow \frac{g(x)-g(y)}{g(z)-g(y)}=\frac{z}{x}
$$

This equation shows that, following the principle of the basic situation (pure ratio), the change in $R=0$, if the rate of change of denominator $y$ equals the rate of growth of numerator $x-z$. The total derivative of $R$ is also zero in the special case when $g(x)=g(z)$ and $z=x$ (the numerator is identically zero).

The change in $R$ is either positive or negative under the following conditions:

$$
\begin{array}{ll}
\text { a. } \quad g(z)>g(y) & \Rightarrow \frac{g(x)-g(y)}{g(z)-g(y)}>\frac{z}{x} \Rightarrow \mathrm{d} R>0 \\
\text { b. } \quad g(z)>g(y) & \Rightarrow \frac{g(x)-g(y)}{g(z)-g(y)}<\frac{z}{x} \Rightarrow \mathrm{d} R<0 \\
\text { c. } \quad & g(z)<g(y) \Rightarrow \frac{g(x)-g(y)}{g(z)-g(y)}<\frac{z}{x} \Rightarrow \mathrm{d} R>0 \\
\text { d. } \quad & g(z)<g(y) \Rightarrow \frac{g(x)-g(y)}{g(z)-g(y)}>\frac{z}{x} \Rightarrow \mathrm{d} R<0
\end{array}
$$

Thus, the sign of the change of $R$ in this situation depends on the relation of the difference $g(x)-g(y)$ to the difference $g(z)-g(y)$, but also on the ratio $z / x$. If numerator $x-Z=0$, then $Z / x=1$ (and $R=0$ ), and the sign of $d R$ is determined by the sign of the difference $g(x)-g(z)$ (change of numerator).

For ratio $R=(x-z) / y$ a steady rate of proportionate change is only reached if (initial values) $x$ and $z$ are growing at the same rate as $g(z)=g(x)$ leading to the following expression:

$$
\begin{aligned}
R(t) & =\frac{x(1+g(x))^{t}-z(1+g(z))^{t}}{y(1+g(y))^{t}} \\
& =\frac{x(1+g(x))^{t}-z(1+g(x))^{t}}{y(1+g(y))^{t}}=\frac{x-z}{y}(1+g(R))^{t} \\
g(R) & =\frac{g(x)-g(y)}{1+g(y)}=\frac{g(z)-g(y)}{1+g(y)}
\end{aligned}
$$

The sign of ratio $R(t)$ depends on the initial values of $x$ and $z$ and time $t$ in the following way:

$$
\begin{aligned}
& R(t)>0=>\frac{x}{z}>\left[\frac{1+g(z)}{1+g(x)}\right]^{t} \\
& \text { a. } \quad g(z)<g(x) \& x>z \Rightarrow R(t)>0 \\
& \text { b. } \quad g(z)>g(x) \& x<z \Rightarrow R(t)<0 \\
& \text { c. } \quad g(z)>g(x) \& x>z \Rightarrow t^{*}<\frac{\log x-\log z}{\log (1+g(z))-\log (1+g(x))} \Rightarrow R\left(t<t^{*}\right)>0 \\
& \text { d. } \quad g(z)<g(x) \& x<z \Rightarrow t^{*}>\frac{\log x-\log z}{\log (1+g(z))-\log (1+g(x))} \Rightarrow R\left(t>t^{*}\right)>0
\end{aligned}
$$


Thus, under given conditions, the ratio can change its sign in the passage of time.

\subsection{Selection of Financial Ratios}

The selection of financial ratios for the further analysis is a challenging task. The set of ratios must be concise enough to allow a detailed analysis in a limited paper but, at the same time, it must cover the most important dimensions traditionally assessed in financial statement analysis. The selected set of ratios is here a consensus but follows the outlines given in a large number of sources dealing with financial statement analysis in various contexts. The number of financial ratios discussed in literature is very high. In failure studies, predictors are typically selected on empirical grounds without any reference to distress theory leading to a wide variety of ratios used in analyses (Balcaen \& Ooghe [12]). Bellovary, Giacomino \& Akers [13] present a review of 165 bankruptcy studies and report that there are in all 674 different financial ratios used in these studies as predictors. Profitability, liquidity, and long-term solvency ratio can be found at the top of the list of used ratios. Thus, the set is of ratios not limited hereto only pure ratios since especially profitability and cash flow ratios are often not positive accounting totals. Table 1 shows a $7 \times 7$ symmetric matrix of potential numerators (columns) and denominators (rows) for financial ratios. These potential components include most important aggregated items from the income statement, the balance sheet, and the cash flow statement. Using these components, it would be possible to construct $(7 \times 7-7) / 2=21$ different financial ratios (combinations of numerators and denominators) when the reciprocals are eliminated. However, the analysis is limited to seven ratios defined in Table 1.

Table 1. Selection of financial ratios.

\begin{tabular}{|c|c|c|c|c|c|c|c|}
\hline \multirow{2}{*}{$\begin{array}{l}\text { Denominator of } \\
\text { a ratio }\end{array}$} & \multicolumn{7}{|c|}{ Numerator of a ratio } \\
\hline & Net sales & Profit & Cash flow & $\begin{array}{c}\text { Current } \\
\text { assets }\end{array}$ & $\begin{array}{l}\text { Total } \\
\text { assets }\end{array}$ & $\begin{array}{c}\text { Current } \\
\text { debt }\end{array}$ & $\begin{array}{l}\text { Total } \\
\text { debt }\end{array}$ \\
\hline Net sales & & $\begin{array}{l}\text { Profit } \\
\text { margin } \\
\text { ratio }\end{array}$ & $\begin{array}{l}\text { Cash flow } \\
\text { to net } \\
\text { sales ratio }\end{array}$ & & & & \\
\hline \multicolumn{8}{|l|}{ Profit } \\
\hline \multicolumn{8}{|l|}{ Cash flow } \\
\hline \multicolumn{8}{|l|}{ Current assets } \\
\hline Total assets & $\begin{array}{l}\text { Capital } \\
\text { turnover\# }\end{array}$ & $\begin{array}{l}\text { Return on } \\
\text { investment } \\
\text { ratio }\end{array}$ & & & & & $\begin{array}{c}\text { Debt to } \\
\text { assets } \\
\text { ratio\& }\end{array}$ \\
\hline Current debt & & & & $\begin{array}{l}\text { Current } \\
\text { ratio }\end{array}$ & & & \\
\hline Total debt & & & $\begin{array}{c}\text { Cash flow } \\
\text { to debt ratio\$ }\end{array}$ & & & & \\
\hline
\end{tabular}

Legend: \# = Capital turnover is also referred to as Total assets turnover; $\not=$ Return on investment ratio (ROI) is also referred to as Return on assets ratio (ROA); \& = Debt to assets ratio is also referred to as Debt ratio; $\S=$ Cash flow to debt ratio is also referred to as cash flow coverage ratio or cash flow leverage ratio. 
The set of selected ratios is consisted of seven financial ratios that can classified in five main categories as summarized in Table 2. Thus, the selected set includes one financial ratio for each of the following main categories: profitability, dynamic liquidity, static liquidity, static solidity (long-term solvency), and dynamic solidity (long-term solvency). In this classification, static financial ratios refer to ratios based on stock (balance sheet) concepts whereas dynamic financial ratios are based on flow concepts (income statement, cash flow). The profitability category has been further classified along the lines of the du Pont triangle system, to include profit margin ratio and capital turnover (compare with Horrigan [14], p. 559). Since profit and cash flow concepts are not positive accounting totals, they have been respectively replaced by the differences between net sales and total expense (NS - TE) and between net sales and cash expense (NS $\mathrm{CE})$. This means that the selected set of ratios includes three pure ratios of form $R=x / y$ and four non-pure (pure component) ratios of form $R=(x-z) / y$. However, for two pure component ratios $x=y$ (NS) so that these ratios can be simplified as $R=1-z / y$. Table 2 also presents the frequencies of studies reviewed by Bellovary, Giacomino \& Akers ([13], p. 42) that include the types of the selected ratios as predictors. The frequencies of the ratios (with different names) that are similar are summed up. The final set of ratios selected for analysis includes the most popular ratios found in the review.

\subsection{Implications}

Empirical time-series studies show that changes in financial ratios of non-failing firms are in a stable environment typically small and random. Beaver ([15], p. 81)

Table 2. Definitions of selected financial ratios.

\begin{tabular}{|c|c|c|}
\hline A. Profitability & Frequencya & Rank\# \\
\hline 1) Return on investment ratio $=\mathrm{ROI}=(\mathrm{NS}-\mathrm{TE}) / \mathrm{TA}=\mathrm{NS} / \mathrm{TA}-\mathrm{TE} / \mathrm{TA}$ & 89 & 1 \\
\hline \multicolumn{3}{|l|}{ Components of ROI: } \\
\hline 2) Profit margin ratio $=\mathrm{PRM}=(\mathrm{NS}-\mathrm{TE}) / \mathrm{NS}=1-\mathrm{TE} / \mathrm{NS}$ & 9 & 21 \\
\hline 3) Capital turnover $=\mathrm{CTR}=\mathrm{NS} / \mathrm{TA}$ & 32 & 7 \\
\hline \multicolumn{3}{|l|}{ B. Dynamic liquidity } \\
\hline 4) Traditional cash flow to sales ratio $=\mathrm{TCF}=(\mathrm{NS}-\mathrm{CE}) / \mathrm{NS}=1-\mathrm{CE} / \mathrm{NS}$ & 9 & 20 \\
\hline \multicolumn{3}{|l|}{ C. Static liquidity } \\
\hline 5) Current ratio $=\mathrm{CRA}=\mathrm{CA} / \mathrm{CD}$ & 51 & 2 \\
\hline \multicolumn{3}{|l|}{ D. Static solidity (long-term solvency) } \\
\hline 6) Debt to assets ratio $=\mathrm{DAR}=\mathrm{TD} / \mathrm{TA}$ & 46 & 3 \\
\hline \multicolumn{3}{|l|}{ E. Dynamic solidity (long-term solvency) } \\
\hline 7) Cash flow to debt ratio $=\mathrm{CFD}=(\mathrm{NS}-\mathrm{CE}) / \mathrm{TD}=\mathrm{NS} / \mathrm{TD}-\mathrm{CE} / \mathrm{TD}$ & 43 & 5 \\
\hline
\end{tabular}

Legend: $a=$ Number of studies reviewed by Bellovary, Giacomino \& Akers (2007) that include a similar ratio; \# = Re-calculated rank in the popularity of ratios in studies reviewed by Bellovary, Giacomino \& Akers (2007); NS = Net sales; TE $=$ Total expenses; CE = Cash expenses; CA = Short-term (current) assets; TA = Total assets; $\mathrm{CD}=$ Short-term (current) debt; $\mathrm{TD}=$ Total debt. 
describes the trend line of financial ratios in these firms having a zero slope and small deviations from the trend line. However, for failing firms changes before failure are usually larger and negative following a kind of systematic failure process. The differences in the means on financial ratios between non-failing and failing firms are evident for at least five years before failure, with the difference increasing as the year of failure approaches (Beaver [15], p. 81). Failing and non-failing firms also tend to report different growth rates (for size measures such as sales and total assets). Typically, in comparable years, the growth rate of non-failing firms is greater than that of failing firms, especially in the last stages of the failure process. In the passage of time, non-failing firms continue to grow while the size of failing firms declines making also profitability descent (Beaver [15], p. 81). However, in failing firms, current and long-term debt continue to grow until failure. Thus, failure process is a systematic process where nearly all financial ratios are associated with each other and change into the same negative direction. Therefore, in failing firms, most financial ratios tend to decline before failure, and ratios are correlated over time. This means that in most failing firms, profitability, liquidity, and long-term solvency ratios as considered here decline during the failure process.

The description of the failure process gives insights for a couple of general conclusions useful for this study. It is obvious that for failing firms the long-term change of the selected seven financial ratios (presented Table 1) will be negative more frequently than for non-failing firms. The change in the financial ratios is based on the change of their components presented in Table 2. The components of the ratios are absolute variables closely associated with the size of the firm. Empirical evidence shows that the trends of different firm size measures are significantly correlated (Dang, Li\& Yang [16], pp. 163-164). Therefore, the trends of the ratio components, which reflect the size, tend to be correlated over time. Consequently, for the selected ratios, it is expected that the trends of their correlated components $(2-3)$ are frequently all either positive or negative. The combinations where some components of a ratio follow a negative trend and some components follow a positive trend, are possible but they are not as frequent as all-positive and all-negative trend combinations. It is also obvious that all-positive combinations are more frequent in non-failing firms than in failing firms whereas all-negative combinations are more frequent in failing firms where the size measures are often declining before failure.

\subsection{Propositions and Hypotheses}

\subsubsection{Pure Ratios}

It is possible to draw propositions (not tested statistically) and hypotheses about the changes in combinations associated with the changes of the selected seven ratios. Five of the ratios are of the pure form either as directly $\mathrm{R}=x / y$ (3 ratios) or through a transformation as $\mathrm{R}=1-z / y$ (2 ratios). For these ratios, the potential propositions are simply based on the relationship between two components $(x$ or $\mathrm{z}$ to $y)$. For the directly pure ratios, a decline of the ratios is positive simply 
if $g(x)>g(y)$ as (3) shows. For the transformed pure ratios, this condition is $g(y)>g(z)$. The general conclusions drawn indicate that the highest frequencies of the component signs will concentrate on all-positive and all-negative trend combinations. However, it is probable that there are differences in the frequencies between the financial ratios. Firstly, the capital turnover ratio (CTR) may not be an efficient indicator of bankruptcy risk. Therefore, the following proposition can be assumed:

\section{Proposition P1:}

The frequencies of the component change signs for CTR do not significantly differ between active and bankrupt firms.

In fact, CTR was included as a predictor in the original Altman [17] Z-model. In a univariate analysis, it was an insignificant predictor. In Z'-model Altman [18] excluded CTR as an industry-sensitive variable from the model due to a potential industry effect.

Secondly, the current ratio (CRA) includes the current debt concept as the denominator. The failure process indicates that an increase of this debt associated with a decrease in current assets is relatively frequent in declining firms. Similarly, a decrease of current debt associated with an increase in current assets may be frequent in firms with an increasing CRA. Therefore, the following proposition can be presented for CRA:

\section{Proposition P2:}

The frequencies of other combinations than all-positive or all-negative trend combinations are frequent for CRA.

Thirdly, this same logic of negative and positive trend components holds also for the debt to assets ratio (DAR) leading to the third proposition as follows:

\section{Proposition P3:}

The frequencies of other combinations than all-positive or all-negative trend combinations are frequent for DAR.

The current set of financial variables also includes two ratios of the non-pure form defined as $\mathrm{R}=(x-z) / y$ where three components are involved with the ratio change. These ratios are the return on investment ratio (ROI) and the cash flow to debt ratio (CFD) which were the most efficient univariate predictors of failure tested by Beaver [15]. The extraction of potential hypotheses for these non-pure ratios will be more complicated and therefore it is separately presented.

\subsubsection{Return on Investment Ratio}

\section{Decreasing ROI}

The first non-pure ratio in the selected set of financial ratios is the return on investment ratio (ROI) that is defined as follows:

$$
\mathrm{ROI}=\frac{\mathrm{NS}-\mathrm{TE}}{\mathrm{TA}}=\frac{\mathrm{NS}}{\mathrm{TA}}-\frac{\mathrm{TE}}{\mathrm{TA}}
$$

where NS is net sales, TE is total expenses (excluding interest and taxes), and TA is total assets (being equal to total capital). 
Following equations ( $7: \mathrm{b} \& \mathrm{~d})$ it can be shown that the change in ROI $(\Delta \mathrm{ROI})$ is negative, when the following conditions hold for the growth rates (trends):

$$
\begin{aligned}
& \text { a. } \quad g(\mathrm{TE})>g(\mathrm{TA}) \Rightarrow \frac{g(\mathrm{NS})-g(\mathrm{TA})}{g(\mathrm{TE})-g(\mathrm{TA})}<\frac{\mathrm{TE}}{\mathrm{NS}} \Rightarrow \Delta \mathrm{ROI}<0 \\
& \text { b. } \quad g(\mathrm{TE})<g(\mathrm{TA}) \Rightarrow \frac{g(\mathrm{NS})-g(\mathrm{TA})}{g(\mathrm{TE})-g(\mathrm{TA})}>\frac{\mathrm{TE}}{\mathrm{NS}} \Rightarrow \Delta \mathrm{ROI}<0
\end{aligned}
$$

which are valid for TE/NS $=1$ or NS-TE $=0$ if

$$
\begin{array}{ll}
\text { a. } & g(\text { TE })>g(\text { TA })>g(\text { NS }) \\
\text { b. } & g(\text { TE })>g(\text { NS })>g(\text { TA }) \\
\text { c. } & g(\text { TA })>g(\text { TE })>g(\text { NS })
\end{array}
$$

In practice, TE/NS is for profitable firms less than unity and for non-profitable (often, failing) firms it exceeds unity. However, the set of conditions (12) can act as an approximation how the trends of the components are associated with a negative change of ROI. For profitable firms, the exact form of conditions (12: a-b) is more stringent than for unprofitable firms whereas that of condition (12: c) is less stringent.

For each condition $(12: \mathrm{a}-\mathrm{c})$ it holds that $g(\mathrm{NS})<g(\mathrm{TE})$ requiring that expenses are growing at a higher rate than net sales leading to decline of profit. Furthermore, conditions (12: a-b) assume that $g(\mathrm{TE})>g(\mathrm{TA})$ leading to that expenses have the highest rate of growth from the three components of ROI. Taking account of the rank order of $g(\mathrm{NS})$ and $g(\mathrm{TA})$ in (12: a-b) the first case can be called "an expense-assets-expansive firm" (EAE firm) whereas the second case is only "an expense-expansive firm" (EE firm). In this way, the trend of net sales can be used as a standard which other trends are compared with. Therefore, the names of the cases do not refer to the absolute height of the growth rates. The third condition (12: c) indicates that $g(\mathrm{TA})$ exceeds $g(\mathrm{TE})$ letting $g(\mathrm{NS})$ being the lowest rate characterizing "an asset-expense-expansive firm" (AEE firm). Empirically, the trends of net sales and total assets can in the long term be close to each other (Dang, Li \& Yang [16], p. 164). However, because TE/NS for declining firms tends to be close to unity with a small variation, it can be expected the trends of the flow concepts, net sales and total expenses, are even closer to each other. Therefore, it may be relatively rare that the growth rate of total assets is located between the growth rates of net sales and total expenses. This actually means that the frequency of the EAE firms (12: a) can be expected to be low. Furthermore, failure process implies that decline or relatively low growth rate of net sales is the main reason for a decline in ROI implying that AEE firms (12: c) are more frequent than only EE firms (12: b) are. This expectation holds for both active (declining) and failing firms. Thus, the following hypothesis $(H 1)$ is presented:

Hypothesis $H 1$ :

For active and failing firms with decreasing ROI, the frequency order of the decline types is the following: 1) Asset-expense-expansive (AEE) firm, 2) Ex- 
pense-expansive (EE) firm, and 3) Expense-asset-expansive (EAE) firm.

\section{Increasing $R O I$}

Equations (7: a \& c) show that the change in ROI ( $\triangle$ ROI) is positive, when the following conditions hold for the growth rates:

$$
\begin{array}{ll}
\text { a. } & g(\mathrm{TE})>g(\mathrm{TA}) \Rightarrow \frac{g(\mathrm{NS})-g(\mathrm{TA})}{g(\mathrm{TE})-g(\mathrm{TA})}>\frac{\mathrm{TE}}{\mathrm{NS}} \Rightarrow \Delta \mathrm{ROI}>0 \\
\text { b. } \quad g(\mathrm{TE})<g(\mathrm{TA}) \Rightarrow \frac{g(\mathrm{NS})-g(\mathrm{TA})}{g(\mathrm{TE})-g(\mathrm{TA})}<\frac{\mathrm{TE}}{\mathrm{NS}} \Rightarrow \Delta \mathrm{ROI}>0
\end{array}
$$

which are valid for TE/NS $=1$ or NS-TE $=0$ if

$$
\begin{array}{ll}
\text { a. } & g(\mathrm{NS})>g(\mathrm{TE})>g(\mathrm{TA}) \\
\text { b. } & g(\mathrm{TA})>g(\mathrm{NS})>g(\mathrm{TE}) \\
\text { c. } & g(\mathrm{NS})>g(\mathrm{TA})>g(\mathrm{TE})
\end{array}
$$

The conditions (14: a-c) are approximations which only hold for TE/NS $=1$. For profitable firms, the exact form of conditions (14: b-c) is less stringent than for unprofitable firms whereas that of condition (14: a) is more stringent due to the higher value of TE/NS.

For each condition $(14: \mathrm{a}-\mathrm{c})$ it is valid that $g(\mathrm{NS})>g(\mathrm{TE})$ so that net sales is growing at a higher rate that expenses leading to increase of profit. Conditions (14: a \& c) imply that net sales has the highest growth rate from the three components. Similarly as for decreasing ROI, the three cases described by (14) can be entitled by the rank order of growth rates in (14: a-c) in the following way: "a sales-expansive firm" (SE firm), "an asset-sales-expansive firm" (ASE firm), and "a sales-asset-expansive firm" (SAE firm). For the same reason as above, it can be expected that in practice the frequency of the SAE firm is low. In this type of increase, the growth rate of assets is located between the growth rates of sales and expenses, which may be rare. For the active firms with increasing ROI it may be typical that the increase is due to an increase in sales rather than in assets. Therefore, it can be assumed for active firms that the frequency of the SE firms is higher than that of the ASE firms. However, the failure process shows that for failing firms an increase in ROI is rare. For failing firms, the components of ROI (size measures) relatively often show a negative growth rate. This kind of negative growth process may lead to an increase in ROI. Thus, for failing firms, it can be expected that the frequency of the ASE firms will exceed that of the SE firms. Thus, the following hypothesis $(H 2)$ is presented:

\section{Hypothesis $H 2$ :}

1) For active firms with increasing ROI, the frequency order of the increase types is the following: a) Sales-expansive (SE) firm, b) Asset-sales-expansive (ASE) firm, and c) Sales-asset-expansive (SAE) firm.

2) For failing firms with increasing ROI, the following order is assumed: a) Asset-sales-expansive (ASE) firm, b) Sales-expansive (SE) firm, and c) Sales-asset-expansive (SAE) firm. 


\subsubsection{Cash Flow to Debt Ratio}

\section{Decreasing CFD}

The second non-pure ratio in the set of the ratios is the cash flow to debt ratio (CFD) that has the following definition:

$$
\mathrm{CFD}=\frac{\mathrm{NS}-\mathrm{CE}}{\mathrm{TD}}=\frac{\mathrm{NS}}{\mathrm{TD}}-\frac{\mathrm{CE}}{\mathrm{TD}}
$$

where NS is net sales, CE is cash expenses (including interest and taxes), and TD is total debt.

Equations (7: $\mathrm{b} \& \mathrm{~d}$ ) show that the change in CFD $(\triangle \mathrm{CFD})$ is negative, when the following conditions hold for the growth rates of the components:

$$
\begin{array}{ll}
\text { a. } & g(\mathrm{CE})>g(\mathrm{TD}) \Rightarrow \frac{g(\mathrm{NS})-g(\mathrm{TD})}{g(\mathrm{CE})-g(\mathrm{TD})}<\frac{\mathrm{CE}}{\mathrm{NS}} \Rightarrow \Delta \mathrm{CFD}<0 \\
\text { b. } \quad g(\mathrm{CE})<g(\mathrm{TD}) \Rightarrow \frac{g(\mathrm{NS})-g(\mathrm{TD})}{g(\mathrm{CE})-g(\mathrm{TD})}>\frac{\mathrm{CE}}{\mathrm{NS}} \Rightarrow \Delta \mathrm{CFD}<0
\end{array}
$$

which are valid for $\mathrm{CE} / \mathrm{NS}=1$ or $\mathrm{NS}-\mathrm{CE}=0$ if

$$
\begin{array}{ll}
\text { a. } & g(\mathrm{CE})>g(\mathrm{TD})>g(\mathrm{NS}) \\
\text { b. } & g(\mathrm{CE})>g(\mathrm{NS})>g(\mathrm{TD}) \\
\text { c. } & g(\mathrm{TD})>g(\mathrm{CE})>g(\mathrm{NS})
\end{array}
$$

In practice, $\mathrm{CE} / \mathrm{NS}$ is rarely exactly equal to unity. However, similarly as for ROI, the set of conditions (17) can now act as approximation how the growth rates of the components are associated with a negative change of CFD. The variation of CE/NS around unity is as a cash-based measure probably greater than that of TE/NS making the approximation more inaccurate than for ROI. For firms with lower CE/NS, the exact form of conditions (17: a-b) is more stringent than for firms with higher CE/NS whereas that of condition (17: c) is less stringent.

For conditions $(17: \mathrm{a}-\mathrm{c})$ it holds that $g(\mathrm{NS})<g(\mathrm{CE})$ so that cash expenses are growing at a higher rate than net sales leading to decline of cash flow. Conditions (17: a-b) assume that $g(\mathrm{CE})>g(\mathrm{TD})$ leading to that expenses have the highest rate of growth. Following the previous principle of taking account of the rank order of growth rates the first case (17: a) can be called as "a cash expense-debt-expansive firm" (CEDE firm) whereas the second case (17: b) is simply "a cash expense-expansive firm" (CEE firm).For the third case (17: c), $g(\mathrm{NS})$ has the lowest growth rate. It can be called as "a debt-cash expense-expansive firm" (DCEE firm). Using the same logic as for ROI it can be expected that the frequency of the CEDE firms (17: a) is low, since $g(\mathrm{NS})$ and $g(\mathrm{CE})$ may be close to each other. The cases where $g(\mathrm{TD})$ is located between these growth rates may be relatively rare. Failure process indicates that for declining firms, especially for failing firms, a high growth rate of debt is typical. Therefore, it will be assumed that the DCEE firms (17: c) show the highest frequency followed by the CEE firms (17: b). Thus, the following hypothesis $(H 3)$ is presented: 


\section{Hypothesis H3:}

For active and failing firms with decreasing CFD, the frequency order of the decline types is the following: 1) Debt-cash expense-expansive firm (DCEE) firm, 2) Cash expense-expansive (CEE) firm, and 3) Cash expense-debt-expansive firm (CEDE) firm.

\section{Increasing $C F D$}

Equations $(7: 1 \& 3)$ show that the change in CFD $(\triangle \mathrm{CFD})$ is positive, when the following conditions hold for the growth rates:

$$
\begin{array}{ll}
\text { a. } & g(\mathrm{CE})>g(\mathrm{TD}) \Rightarrow \frac{g(\mathrm{NS})-g(\mathrm{TD})}{g(\mathrm{CE})-g(\mathrm{TD})}>\frac{\mathrm{CE}}{\mathrm{NS}} \Rightarrow \Delta \mathrm{CFD}>0 \\
\text { b. } \quad g(\mathrm{CE})<g(\mathrm{TD}) \Rightarrow \frac{g(\mathrm{NS})-g(\mathrm{TD})}{g(\mathrm{CE})-g(\mathrm{TD})}<\frac{\mathrm{CE}}{\mathrm{NS}} \Rightarrow \Delta \mathrm{CFD}>0
\end{array}
$$

which are valid for $\mathrm{CE} / \mathrm{NS}=1$ or NS $-\mathrm{CE}=0$ if

$$
\begin{array}{ll}
\text { a. } & g(\mathrm{NS})>g(\mathrm{CE})>g(\mathrm{TD}) \\
\text { b. } & g(\mathrm{TD})>g(\mathrm{NS})>g(\mathrm{CE}) \\
\text { c. } & g(\mathrm{NS})>g(\mathrm{TD})>g(\mathrm{CE})
\end{array}
$$

These conditions are only approximations used to extract hypotheses. For firms with higher CE/NS, the exact form of conditions (19: b-c) is less stringent than for firms with lower CE/NS whereas that of condition (19: a) is more stringent due to the higher value of CE/NS.

For each condition (19: a-c) it is valid that $g(N S)>g(C E)$ so that net sales is growing at a higher rate that cash expenses leading to increase of cash flow. Conditions (19: a \& c) imply that net sales has the highest growth rate from the three components. Similarly, as before, the three cases described by (19) can be entitled by the rank order of growth rates in (19: a-c) respectively as follows: "sales-expansive firm" (SE firm), "debt-sales-expansive firm" (DSE firm), and "sales-debt-expansive firm" (SDE firm). For the same reason earlier, it can be expected that in practice the frequency of the SDE firms is low for both active and failing firms. In these firms, $g(T D)$ is located between $g(\mathrm{NS})$ and $g(C E)$. Furthermore, for the active firms with increasing CFD it may be typical that the growth rate of debt is lower than that of net sales. Thus, for these firms the SE firms may show the highest frequency. The failure process indicates that for failing firms an increase in CFD is rare whereas $g(T D)$ often exceeds $g(N S)$. Therefore, it is expected for failing firms that the DSE firms have the highest frequency. In these firms, one or more components of CFD are often negative. The following hypothesis $(H 4)$ is presented:

\section{Hypothesis H4:}

1) For active firms with increasing CFD, the frequency order of the increase types is the following: a) Sales-expansive (SE) firm, b) Debt-sales-expansive (DSE) firm, and c) Sales-debt-expansive (SDE) firm.

2) For failing firms with increasing CFD, the following order is assumed: a) Debt-sales-expansive (DSE) firm, b) Sales-expansive (SE) firm, and c) Sales-debt-expansive (SDE) firm. 


\section{Empirical Data and Methods}

\subsection{Data}

The empirical data of this study consist of financial statements from Finnish firms extracted from the ORBIS database of Bureau Van Dijk (BvD). The ORBIS database organizes the public data from administrative sources and filters them into various standard formats to facilitate searching and company comparisons. There are many restrictions set for the firms included in the final sample. First, only industrial firms were included so that financial and insurance companies were excluded due to the special nature of their business. Secondly, since the present study concentrates on long-term trend analysis it was required that each sample firms must have continuous time series of financial statements at least for ten years. Thirdly, it was required that the latest year of annual closing of accounts should be between 2012 and 2016 to ensure the freshness of the data.

The research period is characterized by economic difficulties emerged in the Finnish economy. Firstly, the 2008 financial crisis produced one of the most significant economic shocks to the global economy. This crisis touched first in 2007 the U.S. financial sector but the effects spread to several national economies resulting in what has often been called the Great Recession. The crisis can be seen as a major shock to Finland. Secondly, after the financial crisis the second contraction started in the second quarter of 2012 resulting in a period of prolonged recession. This period provides us with an excellent opportunity to assess the hypotheses on the change in major financial ratios, since, due to the strong recession there is a wide variety of firms with either positive or negative ratio changes. Finally, it was required that the total assets of the sample firms must exceed one million Euro at least once during the ten year period. This requirement is set because the assumption of the constant growth rate of ratio components may not be valid for very small firms, which are often characterized with unstable financial development (Balcaen \& Ooghe [12]).

Table 3 presents the description of the final sample. In total, ten-year time series of financial statements from 14,296 industrial firms were extracted from the ORBIS database. However, about $22.3 \%$ of the firms did not have complete series of statements and they were dropped from the sample. Many of the firms were also dropped due to changes in the length of accounting period. Since the components of financial ratios include both flow and stock variables, a change in the length can distort the interpretation of the time series of a ratio. The original data also included firms with an unspecified status such as dissolved firms. These firms were excluded from the final sample that in all includes 9241 industrial firms consisted of 9160 active firms and 81 bankrupt firms. The percent of bankrupt firms $(0.88 \%)$ is consistent with average percent of such firms in Finland. The sample mainly consists of private limited companies. However, it also includes 87 co-operative companies, 9 limited partnership companies, and 91 public limited companies.

The sample is statistically representative with respect to the industry and the 
Table 3. Description of the sample.

\begin{tabular}{|c|c|c|c|}
\hline & & $\mathrm{N}$ & $\%$ \\
\hline \multicolumn{2}{|r|}{ Extracted firms from Orbis } & 14296 & 100.00 \\
\hline \multicolumn{2}{|r|}{ - Firms with missing values in time series } & 3192 & 22.33 \\
\hline \multicolumn{2}{|r|}{ - Firms with changes in length of accounting period } & 1535 & 10.74 \\
\hline \multicolumn{2}{|r|}{ - Active firms in insolvency proceedings } & 8 & 0.06 \\
\hline \multicolumn{2}{|c|}{ - Dissolved firms } & 302 & 2.11 \\
\hline \multicolumn{2}{|r|}{ - Dissolved (merger or take-over) firms } & 6 & 0.04 \\
\hline \multicolumn{2}{|c|}{ - Firms In liquidation } & 12 & 0.08 \\
\hline \multicolumn{2}{|r|}{ Final sample } & 9241 & 64.64 \\
\hline \multicolumn{2}{|r|}{ Active firms } & 9160 & 99.12 \\
\hline \multicolumn{2}{|c|}{+ Bankruptcy firms } & 81 & 0.88 \\
\hline & Final sample & 9241 & 100.00 \\
\hline
\end{tabular}

size of firms in Finland taking account of that very small firms are excluded. The most frequent industries in the sample are wholesale and retail trade (25.1\%), manufacturing (21.1\%), and construction (14.3\%). The median of net sales for the sample firms is 3036 thousand Euro. However, the size distribution is highly skewed so that the average of net sales in the last reporting year is high as 31,742 thousand Euro (with skewness of 25.5). In the last year, the average number of employees is 148 whereas the median number is only 18 (with skewness of 24.2).

\subsection{Statistical Methods}

The analysis of the empirical data will be carried out in several stages. Firstly, the logarithmic-linear trends of the ratio components will be estimated for each of 9241 firms. The selected set of the seven financial ratios is based on seven components as presented in Table 2. These seven positive (as required) components (net sales, total expenses, traditional cash expenses, current assets, total assets, current debt, and total debt) were calculated for the sample firms from the financial statements following standard accounting practices. Total expenses concept is based on the EBIT concept and it does not include interest expenses and taxes (net sales - EBIT). Cash expenses, however, are based on the traditional cash flow concept including these items but neglecting depreciations (net sales net profit + depreciations). For each component $x$, the steady growth rate $g(x)$ (logarithmic trend) is estimated from ten financial statements applying the standard ordinary least squares (OLS) method to the logarithmic time-series of $x$ as follows:

$$
x_{t}=x(1+g(x))^{t} \cdot \mathrm{e}^{\varepsilon} \Rightarrow \log x_{t}=\log x+t \cdot \log (1+g(x))+\varepsilon
$$

where $x$ is the initial value of the component and $e$ is the random residual. The goodness of fit in (20) is assessed by the multiple coefficient of correlation ( $R$ squared). The reliability of the initial value and trend estimates is evaluated by 
$t$-statistics. While the present analysis is based on long-term trend analysis, the change of the seven financial ratios from the first to the last tenth period is calculated using the trend estimates as given by (20). This makes the long-term ratio change consistent with the theoretical framework. The analyses of the ratio changes are separately made for the sample firms with a negative change and for the sample firms with non-negative change. The active and bankrupt firms are analyzed separately.

Secondly, the median growth rates of the ratio components are used to illustrate the average determinants of ratio changes. Thirdly, the co-movement of the denominator and numerator of each ratio is assessed by the median time-series correlation between them. The correlation coefficient for the exact logarithmic-linear time-series of $x$ and $y$ can be calculated in the following way:

$$
\begin{gathered}
\operatorname{COV}(x, y)=\frac{1-((1+g(x))(1+g(x)))^{n+1}}{(n+1)(1-(1+g(x))(1+g(y)))} \\
-\frac{\left(1-(1+g(x))^{n+1}\right)\left(1-(1+g(y))^{n+1}\right)}{(n+1)^{2} g(x) g(y)} \\
\operatorname{VAR}(x)=\frac{1-(1+g(x))^{2(n+1)}}{(n+1) g(x)(2+g(x))}-\frac{\left(1-(1+g(x))^{n+1}\right)^{2}}{(n+1)^{2} g(x)^{2}} \\
\operatorname{COR}(x, y)=\frac{\operatorname{COV}(x, y)}{\sqrt{\operatorname{VAR}(x) \cdot \operatorname{VAR}(y)}}
\end{gathered}
$$

where $g(x)$ and $g(y)$ are the growth rates of $x$ and $y$, respectively, $\operatorname{COV}(x, y)$ is the covariance between them, $\operatorname{VAR}(x)$ is the variance of $x, \operatorname{COR}(x, y)$ is the correlation coefficient between $x$ and $y$, and $n$ is the length of the time series. $\operatorname{VAR}(y)$ can be calculated through (21b) substituting $x$ by $y$.

For the time-series of ratio $R=x / y$ the correlation $\operatorname{COR}(x, y)$ calculated from the actual series is of importance. If the correlation is positive, the simultaneous changes in $x$ (for example debt) and $y$ (for example assets) can partly compensate each other, which can lead to a more stable (constant, increasing, or decreasing) time-series of the ratio (debt-to-assets ratio DAR). If the correlation is negative, the simultaneous changes in $x$ and $y$ will strengthen the changes in the ratio time series. The correlation coefficient is affected by the timing (simultaneity) of the changes in $x$ and $y$, and by the height of these changes. For short time series (such as $n=10$ ), the timing may affect the coefficient more strongly than the height. Table A1 presents experimental values for the coefficient of correlation (21c) for alternative values of $g(x)$ and $g(y)$ when $n=10$ (as in the present data). The experimental values indicate that the correlation coefficient is quite insensitive to the differences in the growth rates of the numerator and the denominator. Therefore, for a perfect timing, the absolute value of this correlation can be close to unity even if the differences in the growth rates (trends) are large. For example, if $g(x)=0.10$ and $g(y)=0.01$, then $\operatorname{COR}(x, y)=0.993(n=10)$. 
Therefore, correlation $\operatorname{COR}(x, y)$ mainly reflects the degree of timing in the changes of $x$ and $y$. However, this interpretation only holds for short time series. When $n=100$ (1000), $C O R(x, y)=0.777$ (0.588).

Fourthly, the three propositions are investigated using the frequencies for the combinations of the signs of the ratio components. For the pure ratios $R=x / y$ and for the transformed pure ratios $R=1-z / y$, each ratio has only two components so that the number of possible sign (negative or non-negative) binary combinations is $2^{2}=4$. However, for the non-pure ratios $R=(x-z) / y$, the number is $2^{3}=8$. Fifthly, the four hypotheses were assessed based on the frequencies of the ordered combinations (permutations) for the rank order of the growth rates of the ratio components. For the pure ratios with two components, there are only two (2!) possible combinations $(x \geq y$ or $y>x$ for pure ratios and $z$ $\geq y$ or $y>z$ for transformed pure ratios) which directly follow from the sign of ratio change $\Delta R$. Therefore, the research hypotheses are only drawn and assessed for the non-pure ratios ( $R O I$ and $C F D$ ) with three components. The number of the ordered combinations of rank orders for these ratios is $3 !=6$.

When analyzing the empirical results, several different tests are used to assess the statistical significance of the findings. First, the significance of the differences in the variable distributions between the active and bankrupt firms is analyzed by the standardized Mann-Whitney U-test (non-parametric Z-test). This median test assesses the null hypothesis that it is equally likely that a randomly selected value from one sample will be less than or greater than a randomly selected value from a second sample. Secondly, the significance of the differences in the proportions of ratio changes between the active and bankrupt firms are tested using the Z-test for the equality of two proportions obtained from independent samples. Thirdly, the association between categorical variables (frequency of combinations and grouping of firms) is tested using the Pearson Chi-Square test to assess whether the variables are independent or related. Finally, the four hypotheses $H 1-H 4$ on the frequency rank orders are assessed by the coefficient of Spearman non-parametric rank correlation. It reflects the consistency between the hypothesized rank order and the actual rank based only on three items. For a rank order of three items, the coefficient of rank correlation can get only four possible values $(1.0,0.5,-0.5$, and -1.0$)$.

\section{Empirical Results}

\subsection{Descriptive Statistics}

Table 4 presents descriptive statistics of the estimation results for the seven ratio components following equation (20). For each of the seven components, the statistical significance ( $t$-value) of the initial value estimate is very high for both the active and bankrupt firms. Statistically, the estimates do not differ between these groups of firms except for the current and total assets. Thus, the size distributions of the groups as measured by other than assets components are quite similar. The statistical significance of the growth (trend) estimates is on average 
Table 4. Median parameters of the logarithmic-linear time series.

\begin{tabular}{|c|c|c|c|c|c|}
\hline \multirow[b]{2}{*}{ Parameter } & \multicolumn{3}{|c|}{ Median of parameter value: } & \multirow[b]{2}{*}{ Z-test ${ }^{\S}$} & \multirow[b]{2}{*}{ p-value } \\
\hline & $\begin{array}{l}\text { Active } \\
\text { firms }\end{array}$ & $\begin{array}{l}\text { Bankrupt } \\
\text { firms }\end{array}$ & $\begin{array}{l}\text { All } \\
\text { firms }\end{array}$ & & \\
\hline \multicolumn{6}{|l|}{ 1) Net sales (NS) } \\
\hline Initial value & 2307.57 & 2087.47 & 2304.18 & -0.692 & 0.4890 \\
\hline t-value & 69.53 & 42.88 & 69.30 & -5.540 & 0.0000 \\
\hline Growth rate & 0.030 & 0.008 & 0.029 & -2.961 & 0.0030 \\
\hline t-value & 1.69 & 0.30 & 1.67 & -4.348 & 0.0000 \\
\hline R-squared & 0.52 & 0.53 & 0.52 & -1.280 & 0.2000 \\
\hline \multicolumn{6}{|l|}{ 2) Total expense (TE) } \\
\hline Initial value & 2093.39 & 1849.79 & 2090.98 & -0.763 & 0.4450 \\
\hline t-value & 72.49 & 47.40 & 72.18 & -5.373 & 0.0000 \\
\hline Growth rate & 0.033 & 0.020 & 0.033 & -1.795 & 0.0730 \\
\hline $\mathrm{t}$-value & 2.02 & 0.64 & 2.01 & -3.512 & 0.0000 \\
\hline $\mathrm{R}$-squared & 0.54 & 0.48 & 0.54 & -1.467 & 0.1420 \\
\hline \multicolumn{6}{|l|}{ 3) Cash expense(CE) } \\
\hline Initial value & 2062.67 & 1819.94 & 2060.12 & -0.730 & 0.4660 \\
\hline $\mathrm{t}$-value & 68.17 & 45.16 & 67.93 & -5.082 & 0.0000 \\
\hline Growth rate & 0.032 & 0.023 & 0.032 & -1.695 & 0.0900 \\
\hline t-value & 1.82 & 0.64 & 1.81 & -3.231 & 0.0010 \\
\hline R-squared & 0.51 & 0.42 & 0.51 & -1.081 & 0.2800 \\
\hline \multicolumn{6}{|c|}{ 4) Short-term (current) assets (SA) } \\
\hline Initial value & 814.03 & 670.05 & 810.45 & -2.402 & 0.0160 \\
\hline t-value & 47.33 & 24.92 & 47.03 & -6.330 & 0.0000 \\
\hline Growth rate & 0.047 & 0.025 & 0.047 & -1.922 & 0.0550 \\
\hline t-value & 2.02 & 0.66 & 2.01 & -3.884 & 0.0000 \\
\hline R-squared & 0.52 & 0.33 & 0.51 & -3.025 & 0.0020 \\
\hline \multicolumn{6}{|l|}{ 5) Total assets (TA) } \\
\hline Initial value & 1382.88 & 1084.98 & 1379.79 & -2.512 & 0.0120 \\
\hline t-value & 72.56 & 37.42 & 72.22 & -7.405 & 0.0000 \\
\hline Growth rate & 0.043 & 0.016 & 0.042 & -1.943 & 0.0520 \\
\hline t-value & 2.61 & 0.71 & 2.58 & -4.127 & 0.0000 \\
\hline R-squared & 0.64 & 0.46 & 0.64 & -3.347 & 0.0010 \\
\hline \multicolumn{6}{|c|}{ 6) Short-term (current) debt (SD) } \\
\hline Initial value & 421.45 & 376.84 & 420.96 & -1.085 & 0.2780 \\
\hline t-value & 32.79 & 28.66 & 32.78 & -2.184 & 0.0290 \\
\hline Growth rate & 0.037 & 0.093 & 0.037 & -3.297 & 0.0010 \\
\hline t-value & 1.23 & 1.92 & 1.24 & -2.234 & 0.0250 \\
\hline R-squared & 0.38 & 0.49 & 0.38 & -1.502 & 0.1330 \\
\hline \multicolumn{6}{|l|}{ 7) Total debt (TD) } \\
\hline Initial value & 699.46 & 584.43 & 697.71 & -1.307 & 0.1910 \\
\hline t-value & 36.35 & 35.51 & 36.35 & -0.314 & 0.7540 \\
\hline Growth rate & 0.030 & 0.088 & 0.031 & -4.431 & 0.0000 \\
\hline t-value & 1.05 & 2.86 & 1.07 & -4.394 & 0.0000 \\
\hline R-squared & 0.41 & 0.54 & 0.41 & -2.954 & 0.0030 \\
\hline
\end{tabular}

Legend: The table shows statistics of the estimation results for Equation (20). $₫=$ Non-parametric Mann-Whitney U test standardized statistic. 
higher for the active firms than for the bankrupt firms except for the current debt and the total debt. The median growth estimates got for the active firms also exceed those got for the bankrupt firms with the exception for the debt components. Thus, failing firms are characterized by a quick growth of debt components but a lower growth of other components leading to increasing indebtedness conforming to the failure process. The average differences in the growth rate between the groups are statistically significant at the level of $5 \%$ only for the net sales, the current debt, and the total debt. For the bankrupt firms, the median growth rate of the net sales is close to zero. The median R-squared in general varies around about $0.40-0.50$ for each time series in both groups. The lowest R-squared is obtained for the current debt in the active firms (0.38) and for the current assets in the bankrupt firms (0.33).

Table 5 presents the median value of the seven financial ratios in the last period available and their median change for the ten-year period. The most significant differences between the active and bankrupt firms are found for DAR, CFD, TCF, ROI and PRM. The statistical test indicates quite an equal significance for the group differences in these ratios. This result indicates that long-term solvency, profitability, and cash-flow ratios are the most efficient univariate indicators of bankruptcy. In general, the ten-year changes of the ratios also show significant differences between the two groups. The only exception is got for CTR that shows an insignificant test value at the level of $5 \%$ for the difference in both the ratio value and its change. These results are in line with the proposition

Table 5. Median financial ratios for the last period and their change for ten-year period.

\begin{tabular}{cccccc}
\hline & \multicolumn{3}{c}{ Median ratio and change: } & & \\
\cline { 2 - 4 } STATUS & $\begin{array}{c}\text { Active } \\
\text { firms }\end{array}$ & $\begin{array}{c}\text { Bankrupt } \\
\text { firms }\end{array}$ & $\begin{array}{c}\text { All } \\
\text { firms }\end{array}$ & Z-test $\$$ & p-value \\
\cline { 2 - 4 } Change in ROI & -0.069 & -0.153 & 0.068 & -11.416 & 0.0000 \\
Profit margin ratio (PRM) & 0.048 & -0.295 & -0.056 & -7.837 & 0.0000 \\
Change in PRM & -0.022 & -0.134 & -0.023 & -7.849 & 0.0000 \\
Capital turnover ratio (CTR) & 1.453 & 1.810 & 1.454 & -1.601 & 0.1090 \\
Change in CTR & -0.161 & -0.360 & -0.162 & -1.166 & 0.2430 \\
Traditional cash flow ratio (TCF) & 0.071 & -0.106 & 0.070 & -11.930 & 0.0000 \\
Change in TCF & -0.016 & -0.156 & -0.016 & -8.915 & 0.0000 \\
Current ratio (CRA) & 1.762 & 0.760 & 1.749 & -9.798 & 0.0000 \\
Change in CRA & 0.144 & -0.433 & 0.138 & -6.247 & 0.0000 \\
Debt to assets ratio (DAR) & 0.505 & 1.290 & 0.509 & -12.785 & 0.0000 \\
Change in DAR & -0.042 & 0.533 & -0.040 & -11.532 & 0.0000 \\
Cash flow to debt ratio (CFD) & 0.204 & -0.114 & 0.201 & -12.269 & 0.0000 \\
Change in CFD & -0.046 & -0.278 & -0.047 & -5.917 & 0.0000 \\
\hline
\end{tabular}

Legend: $\S=$ Non-parametric Mann-Whitney U test standardized statistic. 
$P 1$ that, however, is based on frequencies. The median value of CTR is higher for the bankrupt firms than for the active firms. The highest levels of statistical significance of the test on the differences of the long-term ratio change are found for CFD and DAR conforming to the failure process. However, the differences in the significance between the ratio changes are generally small with the exception for CTR.

\subsection{Long-Term Change of Financial Ratios}

\subsubsection{Return on Investment Ratio}

Table 6 presents statistical analysis of the negative and positive long-term changes in the return on investment ratio (ROI). It shows that a negative change

Table 6. Analysis of changes in return on investment ratio (ROI) for active and bankrupt firms (ten-year period).

\begin{tabular}{|c|c|c|c|c|c|c|}
\hline & \multicolumn{6}{|c|}{ Groups of firms: } \\
\hline & \multicolumn{2}{|c|}{ Active firms: } & \multicolumn{2}{|c|}{ Bankrupt firms: } & \multicolumn{2}{|c|}{ All firms: } \\
\hline & $\begin{array}{c}\text { Decrease } \\
\text { in ROI }\end{array}$ & $\begin{array}{c}\text { Increase } \\
\text { in ROI }\end{array}$ & $\begin{array}{c}\text { Decrease } \\
\text { in ROI }\end{array}$ & $\begin{array}{c}\text { Increase } \\
\text { in ROI }\end{array}$ & $\begin{array}{c}\text { Decrease } \\
\text { in ROI }\end{array}$ & $\begin{array}{c}\text { Increase } \\
\text { in ROI }\end{array}$ \\
\hline \multicolumn{7}{|l|}{ Median of growth rate: } \\
\hline 1) Net sales (NS) & 0.0190 & 0.0548 & 0.0089 & -0.0482 & 0.0189 & 0.0548 \\
\hline 2) Total expenses (TE) & 0.0279 & 0.0465 & 0.0238 & -0.0740 & 0.0279 & 0.0464 \\
\hline 3) Total assets (TA) & 0.0413 & 0.0458 & 0.0229 & -0.0495 & 0.0412 & 0.0457 \\
\hline \multicolumn{7}{|l|}{ Median of time series correlation: } \\
\hline NS-TE \& TA & 0.2368 & 0.4989 & 0.1894 & -0.1143 & 0.2356 & 0.4964 \\
\hline \multicolumn{7}{|l|}{ Frequencies (\%): } \\
\hline 1) $g(\mathrm{NS}) \geq 0 \& g(\mathrm{TE}) \geq 0 \& g(\mathrm{TA}) \geq 0$ & 55.01 & 62.91 & 51.35 & 28.57 & 54.97 & 62.83 \\
\hline 2) $g(\mathrm{NS}) \geq 0 \& g(\mathrm{TE}) \geq 0 \& g(\mathrm{TA})<0$ & 6.71 & 10.67 & 5.41 & 0.00 & 6.70 & 10.65 \\
\hline 3) $g(\mathrm{NS}) \geq 0 \& g(\mathrm{TE})<0 \& g(\mathrm{TA}) \geq 0$ & 0.38 & 2.13 & 0.00 & 0.00 & 0.38 & 2.13 \\
\hline 4) $g(\mathrm{NS}) \geq 0 \& g(\mathrm{TE})<0 \& g(\mathrm{TA})<0$ & 0.00 & 1.36 & 0.00 & 0.00 & 0.00 & 1.36 \\
\hline 5) $g(\mathrm{NS})<0 \& g(\mathrm{TE}) \geq 0 \& g(\mathrm{TA}) \geq 0$ & 3.32 & 0.00 & 2.70 & 0.00 & 3.31 & 0.00 \\
\hline 6) $g(\mathrm{NS})<0 \& g(\mathrm{TE}) \geq 0 \& g(\mathrm{TA})<0$ & 2.14 & 0.07 & 1.35 & 0.00 & 2.13 & 0.07 \\
\hline 7) $g(\mathrm{NS})<0 \& g(\mathrm{TE})<0 \& g(\mathrm{TA}) \geq 0$ & 12.09 & 6.86 & 8.11 & 0.00 & 12.05 & 6.84 \\
\hline 8) $g(\mathrm{NS})<0 \& g(\mathrm{TE})<0 \& g(\mathrm{TA})<0$ & 20.34 & 15.99 & 31.08 & 71.43 & 20.47 & 16.13 \\
\hline Total & 100.00 & 100.00 & 100.00 & 100.00 & 100.00 & 100.00 \\
\hline \multicolumn{7}{|l|}{ Frequencies (\%): } \\
\hline 1) $g(\mathrm{NS}) \geq g(\mathrm{TE}) \geq g(\mathrm{TA})$ & 0.51 & 38.56 & 0.00 & 28.57 & 0.50 & 38.53 \\
\hline 2) $g(\mathrm{NS}) \geq g(\mathrm{TA}) \geq g(\mathrm{TE})$ & 0.00 & 6.93 & 0.00 & 14.29 & 0.00 & 6.95 \\
\hline 3) $g(\mathrm{TE}) \geq g(\mathrm{NS}) \geq g(\mathrm{TA})$ & 32.86 & 10.71 & 31.08 & 0.00 & 32.84 & 10.68 \\
\hline 4) $g(\mathrm{TA}) \geq g(\mathrm{NS}) \geq g(\mathrm{TE})$ & 10.35 & 43.14 & 2.70 & 57.14 & 10.26 & 43.18 \\
\hline 5) $g(\mathrm{TE}) \geq g(\mathrm{TA}) \geq g(\mathrm{NS})$ & 8.01 & 0.00 & 13.51 & 0.00 & 8.08 & 0.00 \\
\hline 6) $g(\mathrm{TA}) \geq g(\mathrm{TE}) \geq g(\mathrm{NS})$ & 48.27 & 0.66 & 52.70 & 0.00 & 48.32 & 0.66 \\
\hline Total & 100.00 & 100.00 & 100.00 & 100.00 & 100.00 & 100.00 \\
\hline Number of firms & 6302 & 2858 & 74 & 7 & 6376 & 2865 \\
\hline$\%$ & 68.80 & 31.20 & 91.36 & 8.64 & 69.00 & 31.00 \\
\hline
\end{tabular}


in bankrupt firms (91.4\%) is more frequent than in active firms $(68.8 \%)$ in a statistically significant way $(\mathrm{p}=0.000)$. The combinations of all-positive and all-negative growth rates of the ratio components (NS, TE, and TA) are the most frequent combinations from the eight alternatives. For the bankrupt firms, all-negative combinations are more frequent than for the active firms. For the negative change of ROI, the combinations of the component growth signs are not associated with the grouping of firms in a statistically significant way $(\mathrm{p}=$ 0.420 ). However, for the positive change a significant association is found ( $\mathrm{p}=$ $0.013)$ although the frequencies of bankrupt firms are few for a statistical analysis (7 firms). The negative change in ROI is mainly based on that the rate of growth in total expenses (TE) exceeds that of net sales (NS). For the active firms, the negative change is strengthened by a rapid increase in total assets (TA). However, for the bankrupt firms the difference in the growth rates of NS and TE is exceptionally large due to a very slow growth of NS. For a positive change in ROI, the growth rate of NS typically exceeds that of TE. For the active firms, all components of ROI show a rapid median growth. However, for the bankrupt firms, the median growth rate of NS is negative but that of TE is even more negative.

The median coefficient of correlation between the numerator and the denominator of ROI indicates for the active firms that the timing of changes is for the positive change of ROI higher than for the negative change. Moreover, this timing is for the active firms higher than for the bankrupt firms. For the bankrupt firms, the median coefficient for the positive change is even negative indicating that the changes of the numerator and the denominator move into the different direction in time: an increase in NS-TE is usually accompanied with a negative change in TA. However, this kind of behavior for TA is not surprising, since the median growth rates of both NS and TE are negative.

Table 6 also presents the frequencies for the six rank order permutations of the component growth rates. For the negative change of ROI, there is a slight association between the frequency distributions and the grouping of firms $(\mathrm{p}=$ $0.105)$ whereas for the positive change any association is not found $(p=0.766)$. The frequency distributions for the positive change of ROI are consistent with hypothesis $H 1$, since for both the active and bankrupt firms the highest frequencies are found for AEE, EE, and EAE firms, in this order. Thus, the coefficient of correlation between the hypothesized and actual rank orders is $1(\mathrm{p}=0.000)$. The frequency for AEE firms is about $50 \%$ and for EE firms about $30 \%$. Thus, in about $50 \%$ of the firms with declining ROI, the growth rates of TA and TE exceed that of NS. For the positive change of ROI in bankrupt firms, hypothesis $H 2 b$ is fully supported by evidence, since the highest frequencies of rank order combinations are found for ASE, SE, and SAE firms following the hypothesized order $(p=0.000)$. The frequency of ASE firms is more than $50 \%$. However, for the active firms, hypothesis $H 2 a$ is not supported, since the actual order is identical with that for the bankruptcy firms, and the frequency of ASE firms slightly exceeds that of SE firms leading to correlation coefficient $0.5(p=0.667)$ with the 
hypothesized order. The frequency of ASE firms exceeds $40 \%$ whereas that of SE firms is slightly below $40 \%$.

\subsubsection{Pure Financial Ratios}

Table 7 presents statistics of the negative and positive long-term changes in the profit margin ratio (PRM) that is the first component of the ROI triangle system. It shows that a negative change is in a statistically significant way $(\mathrm{p}=0.000)$ more frequent for the bankrupt firms (88.9\%) than for the active firms $(64.9 \%)$. The combinations of all-positive and all-negative growth rates of the ratio components (NS and TE) are the most frequent combinations from the four alternatives. For the bankrupt firms, all-negative combinations are more frequent than for the active firms. The combinations of the component growth signs are not significantly associated with the grouping of firms when the change in ROI is negative $(\mathrm{p}=0.299)$. However, for the positive change, they are slightly associated with the grouping $(\mathrm{p}=0.099)$. For the negative change, the median growth rate of total expenses (TE) exceeds that of net sales (NS). In the bankrupt firms, the growth rate of NS is close to zero. For the positive change, the median

Table 7. Analysis of changes in profit margin ratio (PRM) for active and bankrupt firms (ten-year period).

\begin{tabular}{|c|c|c|c|c|c|c|}
\hline & \multicolumn{6}{|c|}{ Groups of firms: } \\
\hline & \multicolumn{2}{|c|}{ Active firms: } & \multicolumn{2}{|c|}{ Bankrupt firms: } & \multicolumn{2}{|c|}{ All firms: } \\
\hline & $\begin{array}{c}\text { Decrease } \\
\text { in PRM }\end{array}$ & $\begin{array}{c}\text { Increase } \\
\text { in PRM }\end{array}$ & $\begin{array}{c}\text { Decrease } \\
\text { in PRM }\end{array}$ & $\begin{array}{l}\text { Increase } \\
\text { in PRM }\end{array}$ & $\begin{array}{c}\text { Decrease } \\
\text { in PRM }\end{array}$ & $\begin{array}{l}\text { Increase } \\
\text { in PRM }\end{array}$ \\
\hline \multicolumn{7}{|l|}{ Median of growth rate: } \\
\hline 1) Net sales (NS) & 0.0199 & 0.0477 & 0.0088 & -0.0461 & 0.0198 & 0.0475 \\
\hline 2) Total expenses (TE) & 0.0300 & 0.0391 & 0.0238 & -0.0505 & 0.0300 & 0.0387 \\
\hline \multicolumn{7}{|c|}{ Median of time series correlation: } \\
\hline NS-TE \& NS & 0.4895 & 0.6817 & 0.4204 & 0.2895 & 0.4890 & 0.6800 \\
\hline \multicolumn{7}{|l|}{ Frequencies (\%): } \\
\hline 1) $g(\mathrm{NS}) \geq 0 \& g(\mathrm{TE}) \geq 0$ & 62.27 & 71.25 & 55.56 & 44.44 & 62.19 & 71.17 \\
\hline 2) $g(\mathrm{NS}) \geq 0 \& g(\mathrm{TE})<0$ & 0.00 & 3.85 & 0.00 & 0.00 & 0.00 & 3.84 \\
\hline 3) $g(\mathrm{NS})<0 \& g(\mathrm{TE}) \geq 0$ & 5.82 & 0.00 & 4.17 & 0.00 & 5.80 & 0.00 \\
\hline 4) $g(\mathrm{NS})<0 \& g(\mathrm{TE})<0$ & 31.90 & 24.90 & 40.28 & 55.56 & 32.00 & 24.98 \\
\hline Total & 100.00 & 100.00 & 100.00 & 100.00 & 100.00 & 100.00 \\
\hline \multicolumn{7}{|l|}{ Frequencies (\%): } \\
\hline 1) $g(\mathrm{NS}) \geq g(\mathrm{TE})$ & 0.00 & 100.00 & 0.00 & 100.00 & 0.00 & 100.00 \\
\hline 2) $g(\mathrm{TE}) \geq g(\mathrm{NS})$ & 100.00 & 0.00 & 100.00 & 0.00 & 100.00 & 0.00 \\
\hline Total & 100.00 & 100.00 & 100.00 & 100.00 & 100.00 & 100.00 \\
\hline Number of firms & 5943 & 3217 & 72 & 9 & 6015 & 3226 \\
\hline$\%$ & 64.88 & 35.12 & 88.89 & 11.11 & 65.09 & 34.91 \\
\hline
\end{tabular}


growth rates of NS and TE are negative in these firms. The median coefficients of correlation indicate that the timing of the changes in NS-TE and NS is in the active firms higher than in the bankrupt firms. For the bankrupt firms, the median coefficient is for the positive change relatively low reflecting a non-systematic change process.

Table 8 shows statistics for the ten-year changes in the capital turnover ratio (CTR) that is the second component of the ROI triangle system. Evidence mainly supports proposition $P 1$, since a negative change in CTR is in the bankrupt firms $(67.9 \%)$ not significantly $(\mathrm{p}=0.121)$ more frequent than in the active firms (59.5\%). However, for the negative change of CTR, the combinations of the component growth signs are significantly $(\mathrm{p}=0.001)$ associated with the grouping of firms. For the positive change, any significant association does not exist ( $p$ $=0.585)$. The all-negative combinations are more frequent for the bankrupt firms than for the active firms. The median growth rates of the components indicate that the negative change of CTR for the active firms is mainly based on the rapid growth in total assets (TA) whereas for the bankrupt firms it comes from the negative growth of net sales (NS). For the both groups, the positive

Table 8. Analysis of changes in capital turnover ratio (CTR) for active and bankrupt firms (ten-year period).

\begin{tabular}{|c|c|c|c|c|c|c|}
\hline & \multicolumn{6}{|c|}{ Groups of firms: } \\
\hline & \multicolumn{2}{|c|}{ Active firms: } & \multicolumn{2}{|c|}{ Bankrupt firms: } & \multicolumn{2}{|c|}{ All firms: } \\
\hline & $\begin{array}{c}\text { Decrease } \\
\text { in CTR }\end{array}$ & $\begin{array}{c}\text { Increase } \\
\text { in CTR }\end{array}$ & $\begin{array}{c}\text { Decrease } \\
\text { in CTR }\end{array}$ & $\begin{array}{c}\text { Increase } \\
\text { in CTR }\end{array}$ & $\begin{array}{c}\text { Decrease } \\
\text { in CTR }\end{array}$ & $\begin{array}{c}\text { Increase } \\
\text { in CTR }\end{array}$ \\
\hline \multicolumn{7}{|l|}{ Median of growth rate: } \\
\hline 1) Net sales (NS) & 0.0168 & 0.0488 & -0.0278 & 0.0285 & 0.0166 & 0.0486 \\
\hline 2) Total assets (TA) & 0.0626 & 0.0120 & 0.0357 & 0.0038 & 0.0625 & 0.0119 \\
\hline \multicolumn{7}{|l|}{ Median of time series correlation: } \\
\hline NS \& TA & 0.7055 & 0.7073 & 0.6448 & 0.6675 & 0.7051 & 0.7067 \\
\hline \multicolumn{7}{|l|}{ Frequencies (\%): } \\
\hline 1) $g(\mathrm{NS}) \geq 0 \& g(\mathrm{TA}) \geq 0$ & 59.77 & 56.40 & 47.27 & 53.85 & 59.64 & 56.39 \\
\hline 2) $g(\mathrm{NS}) \geq 0 \& g(\mathrm{TA})<0$ & 0.00 & 20.68 & 0.00 & 15.38 & 0.00 & 20.64 \\
\hline 3) $g(\mathrm{NS})<0 \& g(\mathrm{TA}) \geq 0$ & 21.41 & 0.00 & 14.55 & 0.00 & 21.34 & 0.00 \\
\hline 4) $g(\mathrm{NS})<0 \& g(\mathrm{TA})<0$ & 18.82 & 22.92 & 38.18 & 30.77 & 19.02 & 22.97 \\
\hline Total & 100.00 & 100.00 & 100.00 & 100.00 & 100.00 & 100.00 \\
\hline \multicolumn{7}{|l|}{ Frequencies (\%): } \\
\hline 1) $g(\mathrm{NS}) \geq g(\mathrm{TA})$ & 0.00 & 100.00 & 0.00 & 100.00 & 0.00 & 100.00 \\
\hline 2) $g(\mathrm{TA}) \geq g(\mathrm{NS})$ & 100.00 & 0.00 & 100.00 & 0.00 & 100.00 & 0.00 \\
\hline Total & 100.00 & 100.00 & 100.00 & 100.00 & 100.00 & 100.00 \\
\hline Number of firms & 5451 & 3709 & 55 & 26 & 5506 & 3735 \\
\hline$\%$ & 59.51 & 40.49 & 67.90 & 32.10 & 59.58 & 40.42 \\
\hline
\end{tabular}


change of CTR is on average obtained by a very low growth of TA. The median coefficients of correlation between the numerator and the denominator are high for each group of firms indicating that the timing of changes in NS and TA is simultaneous supporting a systematic process over time.

Table 9 shows statistical analysis of the long-term changes in the traditional cash flow ratio (TCF).The negative change of TCF is in the bankrupt firms $(90.1 \%)$ significantly $(\mathrm{p}=0.000)$ more frequent than in the active firms $(62.8 \%)$. The combinations of the component growth signs are loosely associated with the grouping of firms when the change of TCF is negative $(\mathrm{p}=0.061)$. However, for the positive change the association is not statistically significant $(\mathrm{p}=0.111)$. For the active firms, the distribution of the combinations is quite similar for the negative and positive change of TCF. For the bankrupt firms, the frequency of the all-negative combinations is higher than for the active firms. The median growth rates of the components indicate that the negative change of TCF for the active firms is mainly based on a rapid growth in cash expenses (CE) while for the bankrupt firms it comes from a very low growth of net sales (NS). However, for the positive change the growth rate of $\mathrm{CE}$ in the active firms is about at the

Table 9. Analysis of changes in traditional cash flow ratio (TCF) for active and bankrupt firms (ten-year period).

\begin{tabular}{|c|c|c|c|c|c|c|}
\hline & \multicolumn{6}{|c|}{ Groups of firms: } \\
\hline & \multicolumn{2}{|c|}{ Active firms: } & \multicolumn{2}{|c|}{ Bankrupt firms: } & \multicolumn{2}{|c|}{ All firms: } \\
\hline & $\begin{array}{c}\text { Decrease } \\
\text { in TCF }\end{array}$ & $\begin{array}{l}\text { Increase } \\
\text { in TCF }\end{array}$ & $\begin{array}{c}\text { Decrease } \\
\text { in TCF }\end{array}$ & $\begin{array}{l}\text { Increase } \\
\text { in TCF }\end{array}$ & $\begin{array}{c}\text { Decrease } \\
\text { in TCF }\end{array}$ & $\begin{array}{l}\text { Increase } \\
\text { in TCF }\end{array}$ \\
\hline \multicolumn{7}{|l|}{ Median of growth rate: } \\
\hline 1) Net sales (NS) & 0.0231 & 0.0395 & 0.0099 & -0.0471 & 0.0230 & 0.0393 \\
\hline 2) Cash expenses (CE) & 0.0322 & 0.0317 & 0.0273 & -0.0644 & 0.0321 & 0.0317 \\
\hline \multicolumn{7}{|l|}{ Median of time series correlation: } \\
\hline $\mathrm{NS}-\mathrm{CE} \& \mathrm{NS}$ & 0.5372 & 0.7117 & 0.4443 & 0.3481 & 0.5345 & 0.7095 \\
\hline \multicolumn{7}{|l|}{ Frequencies (\%): } \\
\hline 1) $g(\mathrm{NS}) \geq 0 \& g(\mathrm{CE}) \geq 0$ & 64.33 & 67.39 & 56.16 & 37.50 & 64.23 & 67.32 \\
\hline 2) $g(\mathrm{NS}) \geq 0 \& g(\mathrm{CE})<0$ & 0.00 & 3.52 & 0.00 & 0.00 & 0.00 & 3.51 \\
\hline 3) $g(\mathrm{NS})<0 \& g(\mathrm{CE}) \geq 0$ & 4.76 & 0.00 & 1.37 & 0.00 & 4.72 & 0.00 \\
\hline 4) $g(\mathrm{NS})<0 \& g(\mathrm{CE})<0$ & 30.91 & 29.09 & 42.47 & 62.50 & 31.05 & 29.17 \\
\hline Total & 100.00 & 100.00 & 100.00 & 100.00 & 100.00 & 100.00 \\
\hline \multicolumn{7}{|l|}{ Frequencies (\%): } \\
\hline 1) $g(\mathrm{NS}) \geq g(\mathrm{CE})$ & 0.00 & 100.00 & 0.00 & 100.00 & 0.00 & 100.00 \\
\hline 2) $g(\mathrm{CE}) \geq g(\mathrm{NS})$ & 100.00 & 0.00 & 100.00 & 0.00 & 100.00 & 0.00 \\
\hline Total & 100.00 & 100.00 & 100.00 & 100.00 & 100.00 & 100.00 \\
\hline Number of firms & 5753 & 3407 & 73 & 8 & 5826 & 3415 \\
\hline$\%$ & 62.81 & 37.19 & 90.12 & 9.88 & 63.05 & 36.95 \\
\hline
\end{tabular}


same level as for the negative change but the median growth rate of NS is much higher. For the bankrupt firms, the median growth rates of NS and CE for the positive change in TCF are negative. The median coefficient of correlation between NS - CE and NS for the positive change on TCF is quite high for the active firms but relatively low for the bankrupt firms.

Table 10 presents statistical analysis of the long-term changes in the current ratio (CRA). The negative change of CRA is in the bankrupt firms $(72.8 \%)$ significantly $(\mathrm{p}=0.000)$ more frequent than in the active firms $(45.8 \%)$. The combinations of the component growth sign are slightly associated with the grouping of firms for the negative change of CRA $(\mathrm{p}=0.104)$ but for the positive change any association is not found $(\mathrm{p}=0.848)$. There are not found any differences in the frequency of the all-negative combinations between the groups. Evidence supports proposition $P 2$, since there are a high frequency of other than all-positive and all-negative growth combinations. For the negative change of CRA, a combination of decreasing current assets (CA) and increasing current debt $(\mathrm{CD})$ is frequent, especially for the bankrupt firms (33.9\%). For the positive change, the frequency of a combination of increasing $\mathrm{CA}$ and decreasing $\mathrm{CD}$ is

Table 10. Analysis of changes in current ratio (CRA) for active and bankrupt firms (ten-year period).

\begin{tabular}{|c|c|c|c|c|c|c|}
\hline & \multicolumn{6}{|c|}{ Groups of firms: } \\
\hline & \multicolumn{2}{|c|}{ Active firms: } & \multicolumn{2}{|c|}{ Bankrupt firms: } & \multicolumn{2}{|c|}{ All firms: } \\
\hline & $\begin{array}{c}\text { Decrease } \\
\text { in CRA }\end{array}$ & $\begin{array}{c}\text { Increase } \\
\text { in CRA }\end{array}$ & $\begin{array}{l}\text { Decrease } \\
\text { in CRA }\end{array}$ & $\begin{array}{c}\text { Increase } \\
\text { in CRA }\end{array}$ & $\begin{array}{l}\text { Decrease } \\
\text { in CRA }\end{array}$ & $\begin{array}{c}\text { Increase } \\
\text { in CRA }\end{array}$ \\
\hline \multicolumn{7}{|l|}{ Median of growth rate: } \\
\hline 1) Current assets (CA) & 0.0350 & 0.0295 & 0.0008 & 0.0326 & 0.0347 & 0.0295 \\
\hline 2) Current debt (CD) & 0.0750 & 0.0065 & 0.1002 & 0.0194 & 0.0756 & 0.0066 \\
\hline \multicolumn{7}{|c|}{ Median of time series correlation: } \\
\hline $\mathrm{CA} \& \mathrm{CD}$ & 0.7348 & 0.6801 & 0.6307 & 0.8428 & 0.7329 & 0.6813 \\
\hline \multicolumn{7}{|l|}{ Frequencies (\%): } \\
\hline 1) $g(\mathrm{CA}) \geq 0 \& g(\mathrm{CD}) \geq 0$ & 59.40 & 53.17 & 47.46 & 59.09 & 59.23 & 53.20 \\
\hline 2) $g(\mathrm{CA}) \geq 0 \& g(\mathrm{CD})<0$ & 0.00 & 27.34 & 0.00 & 22.73 & 0.00 & 27.32 \\
\hline 3) $g(\mathrm{CA})<0 \& g(\mathrm{CD}) \geq 0$ & 22.83 & 0.00 & 33.90 & 0.00 & 22.98 & 0.00 \\
\hline 4) $g(\mathrm{CA})<0 \& g(\mathrm{CD})<0$ & 17.77 & 19.48 & 18.64 & 18.18 & 17.79 & 19.48 \\
\hline Total & 100.00 & 100.00 & 100.00 & 100.00 & 100.00 & 100.00 \\
\hline \multicolumn{7}{|l|}{ Frequencies (\%): } \\
\hline 1) $g(\mathrm{CA}) \geq g(\mathrm{CD})$ & 0.00 & 100.00 & 0.00 & 100.00 & 0.00 & 100.00 \\
\hline 2) $g(\mathrm{CD}) \geq g(\mathrm{CA})$ & 100.00 & 0.00 & 100.00 & 0.00 & 100.00 & 0.00 \\
\hline Total & 100.00 & 100.00 & 100.00 & 100.00 & 100.00 & 100.00 \\
\hline Number of firms & 4197 & 4963 & 59 & 22 & 4256 & 4985 \\
\hline$\%$ & 45.82 & 54.18 & 72.84 & 27.16 & 46.06 & 53.94 \\
\hline
\end{tabular}


high for both groups. The median growth rates show that the negative change of CRA in the bankrupt firms is characterized by a zero growth in CA associated with a rapid growth in $\mathrm{CD}$. The positive change in the active firms is however on average associated with a zero growth in $\mathrm{CD}$. The median correlation between $\mathrm{CA}$ and $\mathrm{CD}$ is high for the both groups indicating a systematic timing pattern.

Table 11 shows statistics for the ten-year changes in the debt to assets ratio (DAR). The positive change of DAR is in the bankrupt firms (90.1\%) significantly $(\mathrm{p}=0.000)$ more frequent than in the active firms $(43.2 \%)$. There is a slight association between the combinations of the component growth signs and the grouping of firms for the positive change in DAR $(p=0.056)$. However, there is not found any association for the negative change $(p=0.613)$. For the negative change of DAR, all-negative combinations are in the active firms more frequent than in the bankrupt firms. Evidence gives support to proposition $P 3$, since there are found frequent combinations for other that all-negative or all-positive ones. For the negative change of DAR, decreasing total assets (TA) and increasing total debt (TD) is quite frequent $(25 \%-26 \%)$ for both groups. For the positive change, increasing TD and decreasing TA is a frequent combination especially for the bankrupt firms conforming to the traditional failure

Table 11. Analysis of changes in debt to assets ratio (DAR) for active and bankrupt firms (ten-year period).

\begin{tabular}{|c|c|c|c|c|c|c|}
\hline & \multicolumn{6}{|c|}{ Groups of firms: } \\
\hline & \multicolumn{2}{|c|}{ Active firms: } & \multicolumn{2}{|c|}{ Bankrupt firms: } & \multicolumn{2}{|c|}{ All firms: } \\
\hline & $\begin{array}{c}\text { Decrease } \\
\text { in DAR }\end{array}$ & $\begin{array}{l}\text { Increase } \\
\text { in DAR }\end{array}$ & $\begin{array}{c}\text { Decrease } \\
\text { in DAR }\end{array}$ & $\begin{array}{l}\text { Increase } \\
\text { in DAR }\end{array}$ & $\begin{array}{c}\text { Decrease } \\
\text { in DAR }\end{array}$ & $\begin{array}{l}\text { Increase } \\
\text { in DAR }\end{array}$ \\
\hline \multicolumn{7}{|l|}{ Median of growth rate: } \\
\hline 1) Total debt (TD) & -0.0052 & 0.0806 & 0.0139 & 0.1005 & -0.0052 & 0.0808 \\
\hline 2) Total assets (TA) & 0.0467 & 0.0373 & 0.0466 & 0.0111 & 0.0467 & 0.0369 \\
\hline \multicolumn{7}{|l|}{ Median of time series correlation: } \\
\hline $\mathrm{TD} \& \mathrm{TA}$ & 0.8154 & 0.9219 & 0.8880 & 0.8657 & 0.8155 & 0.9206 \\
\hline \multicolumn{7}{|l|}{ Frequencies (\%): } \\
\hline 1) $g(\mathrm{TD}) \geq 0 \& g(\mathrm{TA}) \geq 0$ & 47.21 & 67.75 & 62.50 & 56.16 & 47.24 & 67.54 \\
\hline 2) $g(\mathrm{TD}) \geq 0 \& g(\mathrm{TA})<0$ & 0.00 & 15.23 & 0.00 & 24.66 & 0.00 & 15.40 \\
\hline 3) $g(\mathrm{TD})<0 \& g(\mathrm{TA}) \geq 0$ & 26.52 & 0.00 & 25.00 & 0.00 & 26.52 & 0.00 \\
\hline 4) $g(\mathrm{TD})<0 \& g(\mathrm{TA})<0$ & 26.27 & 17.02 & 12.50 & 19.18 & 26.25 & 17.06 \\
\hline Total & 100.00 & 100.00 & 100.00 & 100.00 & 100.00 & 100.00 \\
\hline \multicolumn{7}{|l|}{ Frequencies (\%): } \\
\hline 1) $g(\mathrm{TD}) \geq g(\mathrm{TA})$ & 0.00 & 100.00 & 0.00 & 100.00 & 0.00 & 100.00 \\
\hline 2) $g(\mathrm{TA}) \geq g(\mathrm{TD})$ & 100.00 & 0.00 & 100.00 & 0.00 & 100.00 & 0.00 \\
\hline Total & 100.00 & 100.00 & 100.00 & 100.00 & 100.00 & 100.00 \\
\hline Number of firms & 5200 & 3960 & 8 & 73 & 5208 & 4033 \\
\hline$\%$ & 56.77 & 43.23 & 9.88 & 90.12 & 56.36 & 43.64 \\
\hline
\end{tabular}


process. The median growth rates indicate that the positive change of DAR in the bankrupt firms is characterized by a quick growth in TD but a very slow growth in TA. For the active firms, the negative change of DAR is mainly characterized with a negative growth in TD. The correlation coefficients between TD and TA are very high indicating that a change in TA is systematically associated with a simultaneous change in TD.

\subsubsection{Cash Flow to Debt Ratio}

Table 12 presents statistics for the negative and positive long-term changes in the cash flow to debt ratio (CFD). It shows that a negative change is in bankrupt

Table 12. Analysis of changes in cash flow to debt ratio (CFD) for active and bankrupt firms (ten-year period).

\begin{tabular}{|c|c|c|c|c|c|c|}
\hline & \multicolumn{6}{|c|}{ Groups of firms: } \\
\hline & \multicolumn{2}{|c|}{ Active firms: } & \multicolumn{2}{|c|}{ Bankrupt firms: } & \multicolumn{2}{|c|}{ All firms: } \\
\hline & $\begin{array}{c}\text { Decrease } \\
\text { in CFD }\end{array}$ & $\begin{array}{l}\text { Increase } \\
\text { in CFD }\end{array}$ & $\begin{array}{c}\text { Decrease } \\
\text { in CFD }\end{array}$ & $\begin{array}{l}\text { Increase } \\
\text { in CFD }\end{array}$ & $\begin{array}{c}\text { Decrease } \\
\text { in CFD }\end{array}$ & $\begin{array}{c}\text { Increase } \\
\text { in CFD }\end{array}$ \\
\hline \multicolumn{7}{|l|}{ Median of growth rate: } \\
\hline 1) Net sales (NS) & 0.0206 & 0.0411 & 0.0099 & -0.0471 & 0.0205 & 0.0410 \\
\hline 2) Cash expenses (CE) & 0.0277 & 0.0375 & 0.0273 & -0.0644 & 0.0277 & 0.0374 \\
\hline 3) Total debt (TD) & 0.0525 & -0.0015 & 0.1005 & -0.0080 & 0.0529 & -0.0015 \\
\hline \multicolumn{7}{|l|}{ Median of time series correlation: } \\
\hline NS - CE \& TD & 0.1616 & 0.2345 & -0.2784 & -0.3355 & 0.1571 & 0.2338 \\
\hline \multicolumn{7}{|l|}{ Frequencies (\%): } \\
\hline 1) $g(\mathrm{NS}) \geq 0 \& g(\mathrm{CE}) \geq 0 \& g(\mathrm{TD}) \geq 0$ & 55.67 & 43.56 & 53.42 & 37.50 & 55.64 & 43.55 \\
\hline 2) $g(\mathrm{NS}) \geq 0 \& g(\mathrm{CE}) \geq 0 \& g(\mathrm{TD})<0$ & 6.50 & 26.47 & 2.74 & 0.00 & 6.45 & 26.41 \\
\hline 3) $g(\mathrm{NS}) \geq 0 \& g(\mathrm{CE})<0 \& g(\mathrm{TD}) \geq 0$ & 0.40 & 1.17 & 0.00 & 0.00 & 0.39 & 1.17 \\
\hline 4) $g(\mathrm{NS}) \geq 0 \& g(\mathrm{CE})<0 \& g(\mathrm{TD})<0$ & 0.00 & 1.40 & 0.00 & 0.00 & 0.00 & 1.40 \\
\hline 5) $g(\mathrm{NS})<0 \& g(\mathrm{CE}) \geq 0 \& g(\mathrm{TD}) \geq 0$ & 2.94 & 0.00 & 1.37 & 0.00 & 2.92 & 0.00 \\
\hline 6) $g(\mathrm{NS})<0 \& g(\mathrm{CE}) \geq 0 \& g(\mathrm{TD})<0$ & 1.56 & 0.91 & 0.00 & 0.00 & 1.54 & 0.91 \\
\hline 7) $g(\mathrm{NS})<0 \& g(\mathrm{CE})<0 \& g(\mathrm{TD}) \geq 0$ & 13.41 & 4.52 & 27.40 & 12.50 & 13.60 & 4.54 \\
\hline 8) $g(\mathrm{NS})<0 \& g(\mathrm{CE})<0 \& g(\mathrm{TD})<0$ & 19.53 & 21.97 & 15.07 & 50.00 & 19.47 & 22.03 \\
\hline Total & 100.00 & 100.00 & 100.00 & 100.00 & 100.00 & 100.00 \\
\hline \multicolumn{7}{|l|}{ Frequencies (\%): } \\
\hline 1) $g(\mathrm{NS}) \geq g(\mathrm{CE}) \geq g(\mathrm{TD})$ & 0.08 & 45.40 & 0.00 & 25.00 & 0.07 & 45.36 \\
\hline 2) $g(\mathrm{NS}) \geq g(\mathrm{TD}) \geq g(\mathrm{CE})$ & 0.17 & 4.29 & 12.33 & 0.00 & 0.17 & 4.28 \\
\hline 3) $g(\mathrm{CE}) \geq g(\mathrm{NS}) \geq g(\mathrm{TD})$ & 31.30 & 27.45 & 10.96 & 0.00 & 31.02 & 27.40 \\
\hline 4) $g(\mathrm{TD}) \geq g(\mathrm{NS}) \geq g(\mathrm{CE})$ & 11.81 & 22.42 & 0.00 & 75.00 & 11.65 & 22.52 \\
\hline 5) $g(\mathrm{CE}) \geq g(\mathrm{TD}) \geq g(\mathrm{NS})$ & 5.67 & 0.00 & 4.11 & 0.00 & 5.65 & 0.00 \\
\hline 6) $g(\mathrm{TD}) \geq g(\mathrm{CE}) \geq g(\mathrm{NS})$ & 51.15 & 0.44 & 84.93 & 0.00 & 51.61 & 0.44 \\
\hline Total & 100.00 & 100.00 & 100.00 & 100.00 & 100.00 & 100.00 \\
\hline Number of firms & 5310 & 3850 & 73 & 8 & 5383 & 3858 \\
\hline$\%$ & 57.97 & 42.03 & 90.12 & 9.88 & 58.25 & 41,75 \\
\hline
\end{tabular}


firms $(90.1 \%)$ significantly more frequent $(\mathrm{p}=0.000)$ than in active firms (58.0\%). The combinations of all-positive and all-negative growth rates of the ratio components (NS, CE, and TD) are generally the most frequent combinations from the eight alternatives. However, for the negative change in the bankrupt firms, the combination of decreasing net sales (NS), decreasing cash expenses (CE), and increasing total debt (TD) is more common than the all-negative combination. The combinations of the component growth signs are significantly associated with the grouping of firms for the negative change $(p=0.022)$ but not for the positive change $(p=0.377)$. The median growth rates indicate for the bankrupt firms that a negative change in CFD is mainly due to that the rate of growth in NS is close to zero whereas that of TD is very high. For the positive change, all median rates of growth are negative although the growth rate of TD is only slightly negative.

The median coefficient of time-series correlation between the numerator and the denominator of CFD are low for both groups of firms indicating low degree of timing for changes in NS - CE and TD. These median coefficients for the bankrupt firms are negative showing that typically a decrease in NS - CE is associated with an increase in TD. This kind of behavior is consistent with the traditional bankruptcy process.

Table 12 also presents the frequencies for the six rank order permutations of the component growth rates. There is a significant association between the frequency distributions and the grouping of firms for both the negative $(p=0.000)$ and positive $(p=0.011)$ change of CFD. The frequency distributions for the negative change of CFD are in both groups of firms consistent with hypotheses $H 3$, since the actual frequencies follow the rank order DCEE, CEE, and CEDE firms $(p=0.000)$. The frequency of DCEE firms is for the active firms $51 \%$ and for the bankrupt firms as high as $85 \%$. The hypotheses $H 4 a$ and $H 4 b$ drawn for the positive change of CFD are also supported by evidence, since the rank order of frequencies is for the active firms SE, DSE, and SDE firms $(p=0.000)$ and for the bankrupt firms DSE, SE, and SDE firms $(\mathrm{p}=0.000)$. For the bankrupt firms, the frequency of DSE firms is $75 \%$ but only $22 \%$ for the active firms.

\section{Discussion of Results}

Financial ratio analysis is a very old and widely used tool to analyze the financial health of a business firm. It is based on ratios of financial variables, which summarize information and diminish the effect of size. However, at the same time ratio variables complicate the analysis of the changes in health. The classic critics against financial ratio measures argue that their changes over time cannot be interpreted since the numerator and the denominator can vary simultaneously (Gilman, 1925). The purpose of this study is to take account of this critic and to analyze the long-term changes in seven popular financial ratios. The financial data covers a ten-year period in Finnish firms. This period was characterized by economic difficulties emerged in the Finnish economy. Therefore, also negative 
changes in ratios are frequent making the statistical analysis complete with respect to the signs of changes. The findings showed generally that all-positive and all-negative signs are the most frequent combinations of component signs for each ratio. Thus, the component trends of financial ratios are usually parallel. Five of the seven ratios are pure or transformed pure ratios with two components. However, two of them are non-pure ratios based on three components (a difference of two components in the numerator and one component in the denominator). The former non-pure ratio is the return on investment ratio (ROI) that is the most widely used measure of profitability and the most often used financial variable in failure prediction studies (Bellovary, Giacomino \& Akers [13]). The latter non-pure ratio is the traditional cash flow to debt ratio (CFD) that is found as the best univariate discriminator in many failure prediction studies (Beaver [15]). Since these ratios have three components, the analysis of their changes is more complicated than that of ordinary pure ratio variables. In the next discussion, these non-pure ratios are first discussed.

\subsection{Return on Investment Ratio (ROI)}

For active firms, a decrease in the return on investment ratio (ROI) is typically a consequence of a low growth rate of net sales that goes under the growth rates of total expenses and total assets. Thus, these firms have usually problems in transforming asset resources into sales (sales productivity of assets) or cutting expenses enough to maintain profitability. These problems are reflected by a low degree of timing between changes in profit and total assets. The most frequent situation (48\%) is that the growth rate of total assets exceeds that of total expenses that further exceeds that of net sales (an asset-expense-expansive or AEE firm) emphasizing the difficulties in increasing sales. The second frequent situation $(33 \%)$ is that total expenses has the highest growth rate and total assets the lowest one (an expense-expansive or EE firm) reflecting difficulties in controlling expenses. For bankrupt firms, the findings for a decrease in ROI are quite similar as for active firms although the average growth rate of total assets is lower and that of net sales close to zero. For these firms, the AEE firms (53\%) and the EE firms (31\%) are also the most frequent types. Thus, it seems that for decreasing profitability in terms of ROI the low growth plays a central role. For bankrupt firms, the problems with sales growth are even more serious than for the active firms.

For active firms, a positive change in ROI usually results from a high growth rate of net sales that exceeds that of total expenses. These firms do not have any difficulties in growth and, in a typical situation, the growth rates of all ratio components are positive. The positive development is reflected by a quite high degree of timing between changes in profit and total assets. The most typical situation (43\%) is that the growth rate of total assets exceeds that of net sales and total expenses (an asset-sales-expansive or ASE firm). However, it is also frequent (39\%) that the growth rate of net sales is higher than the growth rate in 
total expenses and total assets (a sales-expansive or SE firm). Thus, a positive change in active firms is typically a consequence of efficient expense control in a growing entity. For bankrupt firms, a positive change is ROI is rare being typically a result of negative growth in all ratio components. The degree of timing in the ratio components is low and negative indicating that an increase in total assets usually causes a decrease in profit. For bankrupt firms, the ASE firms (57\%) and SE firms (29\%) are also the most frequent types of firms. Thus, also in bankrupt firms a positive long-term change in ROI is anyway possible but usually only as a result of negative growth.

\subsection{Cash Flow to Debt Ratio (CFD)}

In active firms, a long-term decrease in the cash flow to debt ratio (CFD) is usually resulted from a low growth rate of sales but also from a high growth of debt. Thus, these firms suffer from difficulties to generate sales but also to constraint getting into debt. The timing between the changes in cash flow and debt is however typically positive (although being low) showing that a deficiency in cash flow is not financed by debt. The most frequent situation (51\%) for these active firms is that the growth rate of total debt exceeds that of cash expenses exceeding further growth rate of net sales (a debt-cash expense-expansive or DCEE firm). The second frequent (31\%) situation is that the growth rate of cash expenses is greater than that of net sales exceeding the growth rate of debt (a cash expense-expansive or CEE firm). These CEE firms do not suffer as strong difficulties with indebting than DCEE firms. For bankrupt firms, the problems associated with a negative change in CFD are similar but significantly more serious. For these firms, the growth rate of sales is typically close to zero although cash expenses grow relative quickly. The most notable warning signal of financial distress is however a very high growth of debt. The timing between cash flow and total debt is negative implying that bankrupt firms usually finance the deficiency in cash flow by debt. The frequency of DCEE firms (85\%) is very high reflecting the dominant role of getting indebted. Consequently, the frequency of SEE firms is low (11\%).

In active firms, a positive change in CDF is typically a result of a high growth rate of net sales and a very low or even negative growth rate of debt. These active firms tend to grow fast but also to keep cash expenses and debt from growing too quick. For these successful firms, it is not rare that increasing net sales and cash expenses are associated with decreasing debt. However, there is usually a positive association in timing between the changes in cash flow and debt. The most typical situation (45\%) is that the growth rate of net sales is greater than that of cash expenses that further exceeds the growth rate of debt (a sales-expansive or SE firm). It is also frequent that cash expenses grow faster than net sales or even that debt shows the highest growth rate (a debt-sales-expansive or DSE firm). For bankrupt firms, all-negative component growth rates are usual. Typically, a decrease in cash flow is associated with an increase in debt characterizing 
the process of getting indebted. In these firms, the situation where a growth rate of debt exceeds growth rates of sales and cash expenses is most frequent resulting in a high frequency of DSE firms (75\%). However, the frequency of SE firms is not small (25\%) indicating that failing firms may also behave like non-failing ones. Anyway, most bankrupt firms follow the typical failure process characterized by a relatively high growth of debt even when the change in CDF is positive. Usually, this happens when the component growth rates are all negative.

\subsection{Pure Financial Ratios}

First, for active firms, a negative change in the profit margin ratio (PRM) is typically resulted from a low growth rate of sales. In many active firms (32\%), both net sales and total expenses show a negative rate of growth. Thus, similarly as for ROI, problems with profit margin in active firms have often their origin in a low rate of sales growth. In bankrupt firms, these problems are similar but even more serious due to a very low growth rate of sales and to the high frequency of all-negative rates of growth (40\%). Symmetrically, a positive change of PRM in active firms is frequently associated with a high growth of sales. However, for bankrupt firms the growth rates of both net sales and total expenses are typically negative (55\%). Usually, the rate of growth is negative but that of total expenses is even more negative. The correlation between the changes in net sales and profit is generally positive and quite high the lowest one being for bankrupt firms when the change in PRM is positive. Thus, this kind of process leading to an increase in PRM is not very systematic for bankrupt firms. In summary, the findings indicate that in the long-term changes of profitability ratios, the growth of sales plays an important role.

Secondly, a negative change of the capital turnover ratio (CTR) in active firms is usually resulted from a low rate of growth in sales associated with a high growth rate of total assets. There are many firms where the growth rate of sales is even negative but the growth rate of assets is positive (21\%). These kinds of bankrupt firms are also quite frequent (15\%) but bankrupt firms with all-negative component growth rates are more usual (38\%). For a positive change in CTR, it is typical for both active and bankrupt firms that the growth rate of total assets is low, quite frequently even negative. In general, the timing of changes in sales and assets is positive and high indicating that a positive change in assets is systematically over time associated with a positive change in sales.

Thirdly, a negative change in the traditional cash flow ratio (TCF) is a result of that the growth rate of cash expenses exceeds that of net sales. For bankrupt firms, the growth rate of net sales is typically very close to zero or even negative. For a positive change in TCF, the growth rates of sales and cash expenses are in active firms usually positive and quite high although all-negative component growth rates are frequent (29\%). However, for bankrupt firms these all-negative combinations are much more usual (63\%). The degree of timing between the changes in cash flow and sales is higher for active firms being high especially for 
a positive change in TCF. It is quite low for bankrupt firms when TCR is increasing.

Fourthly, a negative change in the current ratio (CRA) is in active firms is resulted from a high growth rate of current debt. For bankrupt firms, this rate is even higher and, in addition, the growth of current assets is typically very close to zero or negative. This result clearly shows the dominant role of indebting in the failure process. For a positive change of CRA in active firms, the growth rate of current debt is frequently close to zero whereas for bankrupt firms it is higher reflecting anyway the traditional failure process. In both active and bankrupt firms, the frequency of all-negative component growth rates is generally not very high $(18 \%-19 \%)$. In general, the correlation of changes in current assets and current debt is very high indicating that an increase of current assets is closely associated with an increase in current debt.

Fifthly, a negative change in the debt to assets ratio (DAR) is in active firms typically associated with a very low positive or even negative growth rate of total debt. However, for bankrupt firms this growth rate is usually higher leading to a smaller decrease in DAR. It is also frequent in both active (27\%) and bankrupt (25\%) firms that the growth rate of total debt is negative whereas that of total assets is positive. For the positive change in DAR, the growth rate of total debt is very high for both active and bankrupt firms. When the growth rate of total assets is frequently in bankrupt firms low, the resulted increase in DAR is very strong reflecting the traditional failure process. In general, the correlation between the changes in total assets and total debt is positive and very high for active and bankrupt firms. This indicates that an increase in total assets is strongly linked with an increase in total debt.

\section{Conclusions}

The purpose of this study was to shed light on the long-term change of financial ratios using financial statement data from Finnish firms. Thus, the findings of this study are based on long-term growth rates or trends of the components of seven ratios (trend analysis). The findings generally show that in financial ratio changes the growth of net sales plays a central role. In this study, five of the ratios have net sales as a component being sensitive to its growth rate. There ratios are profitability or cash-flow measures. In the long term, all five ratios tend to decline when the growth of sales is low and to increase when the growth of sales is high. For bankrupt firms, the problems with sales growth are more serious than for active firms. For these firms, the rate of sales growth is often close to zero or even negative. In bankrupt firms, an increase in sales growth-based financial ratios is often emerged in a situation where all ratio components are negative. The current ratio and the debt to assets ratio are the only ratios that do not have net sales as a component. In these ratios, the sign of the change is usually closely associated with the growth of current or total debt. Thus, the growth of debt plays the dominant role in the long-term behavior of these ratios. 
Hence, the findings indicate that financial analysts should pay special attention to the growth of sales when analyzing and predicting the long-term development of profitability and cash-flow ratios. The managers should also pay special attention to sustain a sufficient rate of sales growth in order to control profitability and cash flows. Low or even negative rate of sales growth is a warning signal of failure. Financial analysts should also check that potential improvement in financial ratios is not based on negative growth rates of ratio components that often happens for distressed or failing firms. This kind of improvement may give a wrong signal of the development of a firm. When controlling for short-term and long-term solvency, it is important to monitor the growth rates of current and total debt. High growth rates of debt components are usually warning signals of indebting and potential failure. This lesson is important for both analyzers assessing the performance of the firms in the long term and managers who are responsible for controlling the financial structure.

This study is exposed to several limitations. It only deals with seven financial ratios although there is a multitude of ratios applied in practice. While special attention was paid to select the most important financial ratios for the present analysis, future research should consider also ratios excluded from this study. This study concentrated on the long-term of changes in financial ratios that led to a trend analysis. In future research, also short-term changes should be considered. Moreover, analysis should also be applied to cross-sectional differences in ratios between firms in addition to time-series differences analyzed in this study. This study only considers Finnish firms on a period characterized by economic difficulties. Samples for different countries and periods should be analyzed as well. Moreover, attention should be paid to the behavior of financial ratios in different industries. Finally, a small sample of bankrupt firms were used to detect the warning signals of failure. In future research, larger samples of failing firms should be used to generalize the results for bankrupt firms.

\section{Conflicts of Interest}

The author declares no conflicts of interest regarding the publication of this paper.

\section{References}

[1] Horrigan, J.O. (1968) A Short History of Financial Ratio Analysis. The Accounting Review, 43, 284-294.

[2] Gilman, S. (1925) Analyzing Financial Statements. The Ronald Press Company, New York.

[3] Whittington, G. (1980) Some Basic Properties of Accounting Ratios. Journal of Business Finance and Accounting, 7, 219-232. https://doi.org/10.1111/j.1468-5957.1980.tb00738.x

[4] Barnes, P. (1987) The Analysis and Use of financial Ratios: A Review Article. Journal of Business Finance \& Accounting, 14, 446-461. https://doi.org/10.1111/j.1468-5957.1987.tb00106.x 
[5] Tippett, M. and Whittington, G. (1995) An Empirical Evaluation of an Induced Theory of Financial Ratios. Accounting and Business Research, 25, 208-222. https://doi.org/10.1080/00014788.1995.9729943

[6] Whittington, G. and Tippett, M. (1999) The Components of Accounting Ratios as Co-Integrated Variables. Journal of Business Finance and Accounting, 26, 1245-1273. https://doi.org/10.1111/1468-5957.00296

[7] Ioannides, C., Peel, D. and Peel, M. (2003) The Time Series Properties of Financial Ratios: Lev Revisited. Journal of Business Finance and Accounting, 30, 699-714. https://doi.org/10.1111/1468-5957.05201

[8] Peel, D., Peel, M. and Venetis, I. (2004) Further Empirical Analysis of the Time Series Properties of Financial Ratios Based on a Panel Data Approach. Applied Financial Economics, 14, 155-163. https://doi.org/10.1080/0960310042000187342

[9] McLeay, S. and Stevenson, M. (2009) Modelling the Longitudinal Properties of Financial Ratios. Applied Financial Economics, 19, 305-318. https://doi.org/10.1080/09603100802167270

[10] Lev, B. and Sunder, S. (1979) Methodological Issues in the Use of Financial Ratios. Journal of Accounting and Economics, 1, 187-210. https://doi.org/10.1016/0165-4101(79)90007-7

[11] Trigueiros, D. (1995) Accounting Identities and the Distribution of Ratios. British Accounting Review, 27, 109-126. https://doi.org/10.1006/bare.1994.0006

[12] Balcaen, S. and Ooghe, H. (2006) 35 Years of Studies on Business Failure: An Overview of the Classic Statistical Methodologies and Their Related Problems. The British Accounting Review, 38, 63-93. https://doi.org/10.1016/j.bar.2005.09.001

[13] Bellovary, J.L., Giacomino, D.E. and Akers, M.D. (2007) A Review of Bankruptcy Prediction Studies: 1930 to Present. Journal of Financial Education, 1, 3-41.

[14] Horrigan, J.O. (1965) Some Empirical Bases of Financial Ratio Analysis. The Accounting Review, 40, 558-568.

[15] Beaver, W.H. (1966) Financial Ratios as Predictors of Failure, Empirical Research in Accounting, Selected Studies. Journal of Accounting Research, 4, 71-111. https://doi.org/10.2307/2490171

[16] Dang, C., Li, Z. and Yang, C. (2018) Measuring Firm Size in Empirical Corporate Finance. Journal of Banking \& Finance, 86, 159-176. https://doi.org/10.1016/j.jbankfin.2017.09.006

[17] Altman E.I. (1968) Financial Ratios, Discriminant Analysis and the Prediction of Corporate Bankruptcy. The Journal of Finance, 23, 589-609. https://doi.org/10.1111/j.1540-6261.1968.tb00843.x

[18] Altman, E.I. (1983) Corporate Financial Distress. A Complete Guide to Predicting, Avoiding, and Dealing with Bankruptcy. Wiley Interscience. John Wiley and Sons. 


\section{Appendix}

Table A1. Pearson correlation coefficients for steady time series $(n=10)$. (a) Positive growth rates for $x$ and $y$, (b) positive growth rates for $x$ and negative growth rates for $y$.

(a)

\begin{tabular}{lllllll}
\hline \multirow{2}{*}{$g(\boldsymbol{x})$} & \multicolumn{6}{c}{$g(y)$} \\
\cline { 2 - 6 } & $\mathbf{0 . 0 1 0 0}$ & $\mathbf{0 . 0 2 5 0}$ & $\mathbf{0 . 0 5 0 0}$ & $\mathbf{0 . 0 7 5 0}$ & $\mathbf{0 . 1 0 0 0}$ & $\mathbf{0 . 1 2 5 0}$ \\
\hline $\mathbf{0 . 0 1 0 0}$ & 1.0000 & & & & & \\
$\mathbf{0 . 0 2 5 0}$ & 0.9998 & 1.0000 & & & & \\
$\mathbf{0 . 0 5 0 0}$ & 0.9988 & 0.9995 & 1.0000 & & & \\
$\mathbf{0 . 0 7 5 0}$ & 0.9969 & 0.9982 & 0.9996 & 1.0000 & & \\
$\mathbf{0 . 1 0 0 0}$ & 0.9943 & 0.9961 & 0.9983 & 0.9996 & 1.0000 & \\
$\mathbf{0 . 1 2 5 0}$ & 0.9910 & 0.9933 & 0.9963 & 0.9984 & 0.9996 & 1.0000 \\
\hline
\end{tabular}

(b)

\begin{tabular}{|c|c|c|c|c|c|c|}
\hline \multirow{2}{*}{$g(x)$} & \multicolumn{6}{|c|}{$g(y)$} \\
\hline & -0.0100 & -0.0250 & -0.0500 & -0.0750 & -0.1000 & -0.1250 \\
\hline 0.0100 & -0.9997 & -0.9990 & -0.9970 & -0.9939 & -0.9896 & -0.9841 \\
\hline 0.0250 & -0.9990 & -0.9980 & -0.9954 & -0.9917 & -0.9867 & -0.9806 \\
\hline 0.0500 & -0.9972 & -0.9956 & -0.9920 & -0.9873 & -0.9814 & -0.9743 \\
\hline 0.0750 & -0.9946 & -0.9924 & -0.9879 & -0.9822 & -0.9754 & -0.9673 \\
\hline 0.1000 & -0.9913 & -0.9886 & -0.9831 & -0.9765 & -0.9688 & -0.9598 \\
\hline 0.1250 & -0.9873 & -0.9840 & -0.9777 & -0.9703 & -0.9616 & -0.9518 \\
\hline
\end{tabular}

